Research Article

\title{
Dynamic Fracture Experiment of Fractured Rock under Dynamic Loading
}

\author{
Yanbing Wang $\mathbb{D}^{1,2,3}$ Xingyuan Zhou, ${ }^{1,4}$ Ji Kong, ${ }^{1}$ and Bingbing Yu ${ }^{1}$ \\ ${ }^{1}$ School of Mechanics and Architecture Engineering, China University of Mining and Technology (Beijing), Beijing 100083, China \\ ${ }^{2}$ Shandong Key Laboratory of Civil Engineering Disaster Prevention and Mitigation, \\ Shandong University of Science and Technology, Qingdao 266590, China \\ ${ }^{3}$ State Key Laboratory for Geomechanics and Deep Underground Engineering, Beijing 100083, China \\ ${ }^{4}$ The Institute of Crustal Dynamics, CEA, Beijing 100085, China
}

Correspondence should be addressed to Yanbing Wang; ceowyb818@163.com

Received 26 May 2019; Accepted 9 January 2020; Published 14 February 2020

Academic Editor: Ivo Caliò

Copyright (c) 2020 Yanbing Wang et al. This is an open access article distributed under the Creative Commons Attribution License, which permits unrestricted use, distribution, and reproduction in any medium, provided the original work is properly cited.

In order to examine the dynamic mechanical properties, dynamic crack proposition process, and energy loss of fractured rock under dynamic loading, the specimens with different fracture dig angles were processed with $\Phi 50 \mathrm{~mm} \times 50 \mathrm{~mm}$ cylindrical sandstone, the impact loading test was conducted on $50 \mathrm{~mm}$ stem diameter split Hopkinson pressure bar (SHPB) experiment platform, and the whole process of crack propagation and dynamic failure was recorded using a high-speed camera. As a result, the dynamic mechanical properties such as stress wave fluctuation characteristics, peak strength and stress-strain relationship, crack initiation angle, stress and other dependencies with prefabricated fracture angle of the prefabricated fracture specimens under high strain rate were obtained, and the incident energy, absorbed energy, and energy absorption rates were compared to investigate the energy loss law in the dynamic loading; on the contrary, the effects of different loading rates on the dynamic mechanical properties of the sandstone specimens were identified, and finally a set of findings were presented.

\section{Introduction}

Rocks are naturally produced solid aggregates that are composed of one or more minerals, subject to the geological effects of the earth's internal external forces $[1,2]$. There are a number of defects with different sizes and shapes in rocks, subject to the combined action of external loading and natural environment, and the defects in rocks may be easily merged and expanded into joints and in turn. The presence of joints leads to discontinuity, nonuniformity, and anisotropy of rocks and substantially changes the stress wave propagation velocity in rocks, thereby altering many properties of rocks and resulting in instability failure of rocks. Under static loading, the failure process of rocks and various physical and mechanical properties of rocks can be obtained from the rock full stress-strain curves derived from uniaxial compression, triaxial compression, and other static load tests; under dynamic loading, the dynamic mechanical properties during the rock fracture process can be obtained from the impact test. The rock fracture process refers to the process from energy acquisition to energy release. Subject to external loading, rock first absorbs energy to deform and then releases energy to break and fail. Even if the transient stress applied on rocks is very large, rocks cannot acquire enough energy in a short time. Thus, the dynamic mechanical properties of rocks are sharply different from the properties under static loading. In the engineering works of mining, foundation pit excavation, slope support, engineering blasting, and geological exploration, rock mass is always subject to dynamic loading. For example, the degree of rock breaking caused by blasting should be precisely controlled, and the rock breaking fragmentation, blasted pile shape, and blasting volume are required to be reasonably controlled in the work of engineering blasting so that the mechanical efficiency can be fully used. In this sense, an attempt to investigate the dynamic properties of fractured 
rocks is theoretically and practically significant to properly assessing the engineering stability and safety and gaining an insight into the instability failure mechanism of engineering rock mass.

With a view to the effects of prefabricated fractures on rock mechanical properties, Yang and He [3] derived the strength and stress-state variation of multifracture rock from the single-fracture rock strength and internal stress change. Zhang et al. [4] constructed a localized progressive damage model with fractured rock materials to investigate the evolutionary process from local fracture to macrofailure zone in the presence of failure of fractured rock-like materials and made a theoretical verification for the proposed localized progressive damage model through test. Yang et al. [5] analyzed all mechanical parameters of the sandstone specimens with pore fractures by the uniaxial compression test, derived the relationship between sandstone strength, strain, and pore fracture size, discussed the crack propagation process of the specimens, and plotted the stress-strain curves of different sandstone specimens with pore fractures. Su et al. [6] conducted a uniaxial compression test on sandstone specimens with longitudinal fractures, analyzed the properties of the specimens from the perspective of strength and strain, discussed the crack propagation process during the compression process, compared the mechanical properties of rock-like fractured specimens with different dig angles, and examined an array of mechanical properties and the relationship between crack initiation angle, crack propagation process, and prefabricated fracture angle. Li et al. [7, 8] conducted a tensile test of layered sandstone with different dip angles relative to the bedding plane, examined the effects of different dip angles relative to the bedding plane on stress, strain, strength, and other physical and mechanical properties of sandstone, and identified all dynamic mechanical properties of the marble with prefabricated fractures by the impact test and how the energy changed during the impact process. Xia et al. [9] experimented on the granite specimens with nonconnected fractures by the true triaxial test and derived how the fractured rocks deformed under loading. Xu [10] investigated the properties of jointed rocks by ultrasonic detection, derived how wave velocity, amplitude, and other factors changed, and studied the mechanical properties of rocks by the uniaxial loading test. Xie et al. [11] reported that energy dissipation and release are the nature of material deformation failure and provided the criterion for strength loss and overall failure. Gao et al. [12] impacted granite with SHPB bar to examine the relationship between dynamic fracture toughness and loading rate of rocks. Deng et al. [13] investigated the damage mechanical properties of rocks and the law of energy dissipation under dynamic loading by the SHPB impact test and found that the degree of rock fracture was positively correlated with strain rate. Wang et al. [14-16] investigated the effects of connected joint dig angle, joint thickness, joint filling material, and strain rate on the dynamic mechanical properties of rocks with SHPB experimental rig. However, of the existing research findings, very few researchers studied the crack propagation and coalescence of fractured rocks under high strain rate with SHPB experimental rig.

In this paper, the specimens with different fracture dig angles were processed with $\Phi 50 \mathrm{~mm} \times 50 \mathrm{~mm}$ cylindrical sandstone, the impact loading test was conducted on $50 \mathrm{~mm}$ stem diameter split Hopkinson pressure bar (SHPB) experiment platform, and the whole process of crack propagation and dynamic failure was recorded using a high-speed camera. According to the SHPB test results, the engineering mechanical properties of rocks were inferred and some results were obtained.

\section{Experimental Design}

2.1. Preparation of Specimens. In this experiment, the specimens were sourced from Jiaoxi Township, Liuyang City, Hunan, with an average density of $2500 \mathrm{~kg} / \mathrm{m}^{3}$ and a uniaxial compressive strength of about $75 \mathrm{MPa}$. Cylindrical sandstone specimens were selected, with a diameter of $50 \mathrm{~mm}$ and a height of $50 \mathrm{~mm}$. The prefabricated fracture dip angle $\alpha$ of the sandstone specimen was the angle between the end face of the sandstone specimen and the extension line of the fracture. The length of prefabricated fracture was $l=10 \mathrm{~mm}$, and its width was $1 \mathrm{~mm}$, as shown in Figure 1 . By the different prefabricated factures, 15 pieces of specimens were divided into 3 groups: (1) 5 specimens with prefabricated fractures at a dip angle of $45^{\circ}$ were divided into Group a, denoted as a1, a2, a3, a4, and a5; (2) 5 specimens with prefabricated fractures at a dip angle of $90^{\circ}$ were divided into Group b, denoted as b1, b2, b3, b4, and b5; and (3) 5 specimens with prefabricated fractures at a dip angle of $0^{\circ}$ were divided into Group c, denoted as c1, c2, c3, c4, and c5 (one of each group was reserved for backup).

2.2. Experimental Rig. This experiment was conducted on the $\Phi 50 \mathrm{~mm} \times 50 \mathrm{~mm}$ splitting Hopkinson pressure bar (SHPB) experimental rig in China University of Mining and Technology (Beijing), and the loading methods on the sandstone specimens with prefabricated fractures at $0^{\circ}, 45^{\circ}$, and $90^{\circ}$ are shown in Figure 2. The incident bar, the transmission bar, and the punch are made of siliconmanganese steel, the longitudinal wave velocity was $5100 \mathrm{~m} / \mathrm{s}$, and the elastic modulus was $210 \mathrm{GPa}$. The high-speed camera used in high-speed photography unit was Kirana-5M, the resolution for single shot was fixed at 924 pixel $\times 768$ pixel, the number of acquired images was 180, and the fastest shooting speed was $5000000 \mathrm{fp}$. The shooting frame for the high-speed photography unit was set as $500000 \mathrm{fps}$, namely, one image was photographed every $2 \mu \mathrm{s}$, and 180 images were acquired from each piece of specimens in order to accurately and clearly record the dynamic crack propagation development in this experiment.

2.3. Experimental Procedure. The experiment commenced after the high-speed photography unit and SHPB experimental rig were set up and adjusted. 3 groups of specimens were placed between the input bar and output bar, respectively, as shown in Figure 3. Each group of sandstone 


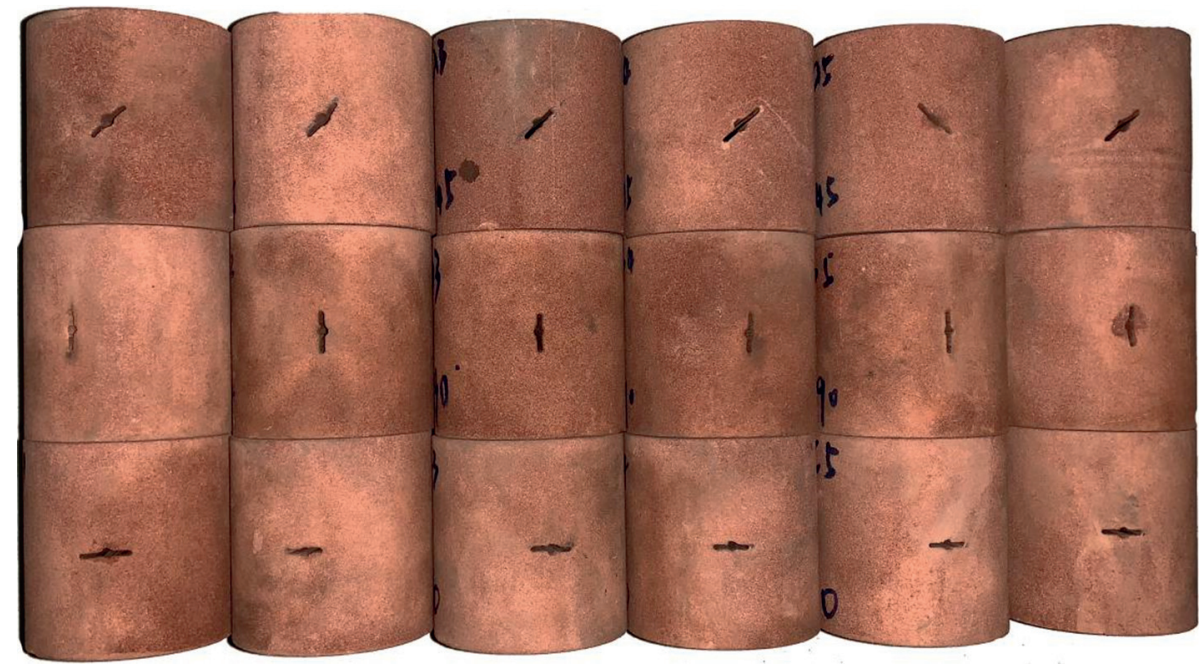

FIgURE 1: Specimens with prefabricated fractures at different dig angles.

specimens with prefabricated fractures was impacted with the impact pressure of $0.25 \mathrm{MPa}, 0.28 \mathrm{MPa}, 0.31 \mathrm{MPa}$, $0.34 \mathrm{MPa}$, and $0.37 \mathrm{MPa}$, respectively. Specifically, Specimen a1 was impacted with $0.25 \mathrm{MPa}$, Specimen a2 was impacted with $0.28 \mathrm{MPa}$, Specimen a3 was impacted with $0.31 \mathrm{MPa}$, Specimen a4 was impacted with $0.34 \mathrm{MPa}$, and Specimen a5 was impacted with $0.37 \mathrm{MPa}$. The specimens in Groups b and $c$ were subject to the same impact pressures, and the dynamic crack propagation process of each specimen was recorded by the high-speed photography unit. To study the effects of the loading rate on the stress and crack propagation process of specimens, because the loading rate was controlled by the impact pressure, the loading rate was changed by changing the impact pressure. The loading rates of the specimens under different impact pressures are given in Table 1. As is shown from Table 1, under the same impact pressure, the loading rates applied on the specimens were basically the same. Therefore, the average value of the loading rates in these three groups under the same pressure was selected as the loading rate. In other words, to examine the effects of loading rate on the specimens, the loading rates of $9.7 \mathrm{~m} / \mathrm{s}, 10.6 \mathrm{~m} / \mathrm{s}, 11.4 \mathrm{~m} / \mathrm{s}, 12.2 \mathrm{~m} / \mathrm{s}$, and $12.8 \mathrm{~m} / \mathrm{s}$ were selected, respectively.

\section{Analysis of Experimental Results}

3.1. Analysis of Stress Equilibrium. In conformity with the one-dimensional stress wave assumption and the uniformity assumption, the incident wave, the reflected wave in the incident bar, and the transmitted wave in the transmission bar were measured and recorded using a dynamic strain gauge, and then the stress-strain relationship of specimens was derived according to the one-dimensional stress wave theory $[17,18]$. According to the calculation of the electrical signal conversion, the waveform signals transmitted by the stress wave in the test specimens can be obtained. For the purpose of this work, a set of typical waveform signals were extracted from each of the three groups for the analysis of stress equilibrium, the waveform signals, and the stress equilibrium relationship in respect of a1, b1, and $c 1$ are shown in Figure 4, respectively.

In a1, the fronts of the waveform curves for the incident voltage and the transmitted voltage basically overlapped, the incident wave first reached the valley, the transmitted voltage and the reflected voltage almost appeared at the same time; in the stress equilibrium graph, the superimposition curves for the incident stress and the reflected stress basically overlapped with that for the transmitted stress; in b1, the fronts of the waveform curves for the incident voltage and the transmitted voltage also overlapped, and the incident voltage first reached the peak. By the time that the incident voltage returned back to about $0 \mathrm{~V}$, the transmitted voltage and the reflected voltage began to form, the transmitted voltage first reached the peak, while the reflected voltage was the last to reach the peak; in the stress equilibrium graph, the superimposition curves for the incident stress and the reflected stress basically overlapped with that for the transmitted stress; in c1, the fronts of the waveform curves for the incident voltage and the transmitted voltage also basically overlapped, the incident voltage change was also basically consistent with that in al and b1, but there was a small decline before the reflected voltage and the transmitted voltage reached the peak; in the stress equilibrium graph, although the superimposition curves for the incident stress and the reflected stress basically overlapped with that for the transmitted stress, there was also a small fluctuation, which may be attributed to a slight deformation formed transiently as the specimen came into contact with the bar, thus impacting the transfer of the reflected wave and the transmitted wave. By analyzing the waveform curves and the stress equilibrium graphs for the incident, reflected, and transmitted voltages of these three specimens, it was found that their prepeak curves basically overlapped, and the transmitted stress curves basically overlapped with the superimposition curves for the incident stress and the reflected stress. As a result, the specimens should meet the stress equilibrium condition in the initial loading stage. According to the one-dimensional stress wave theory, the stress, strain, 

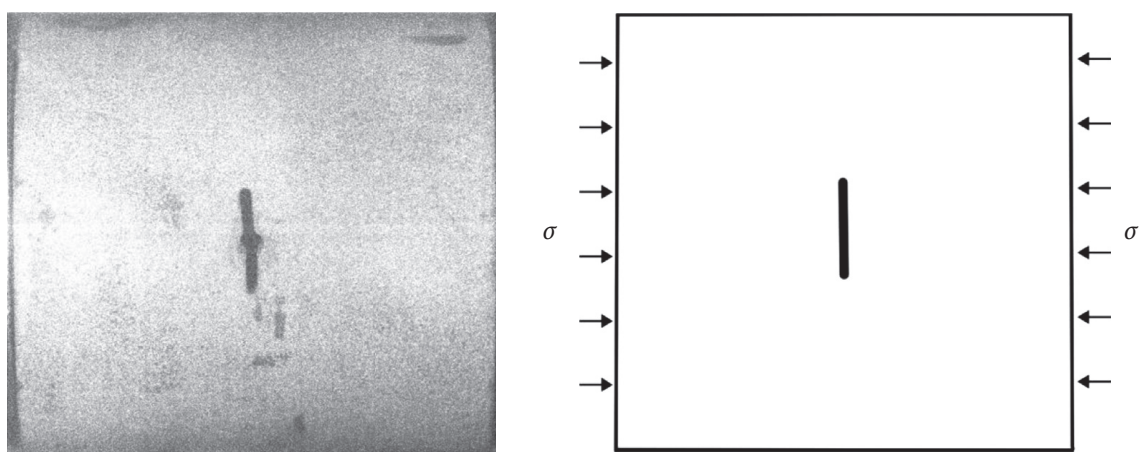

(a)
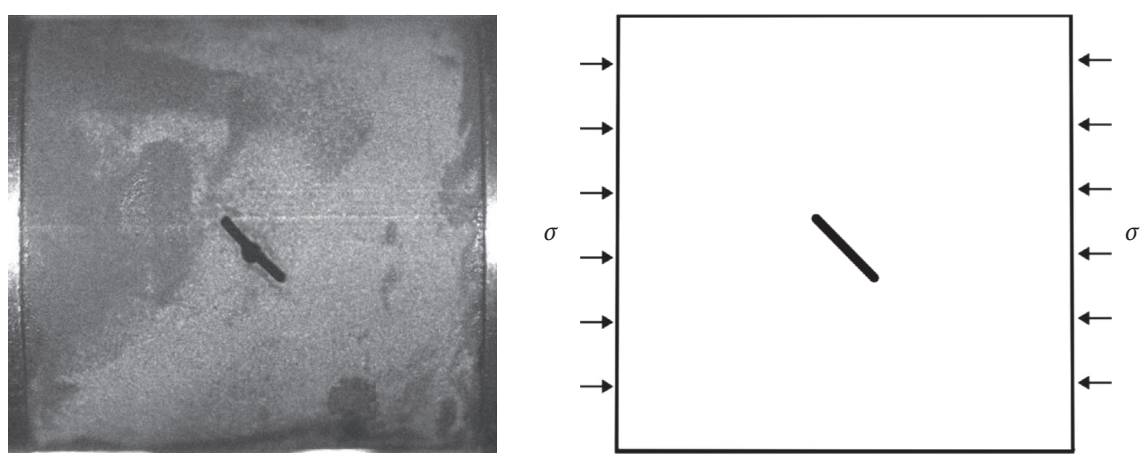

(b)
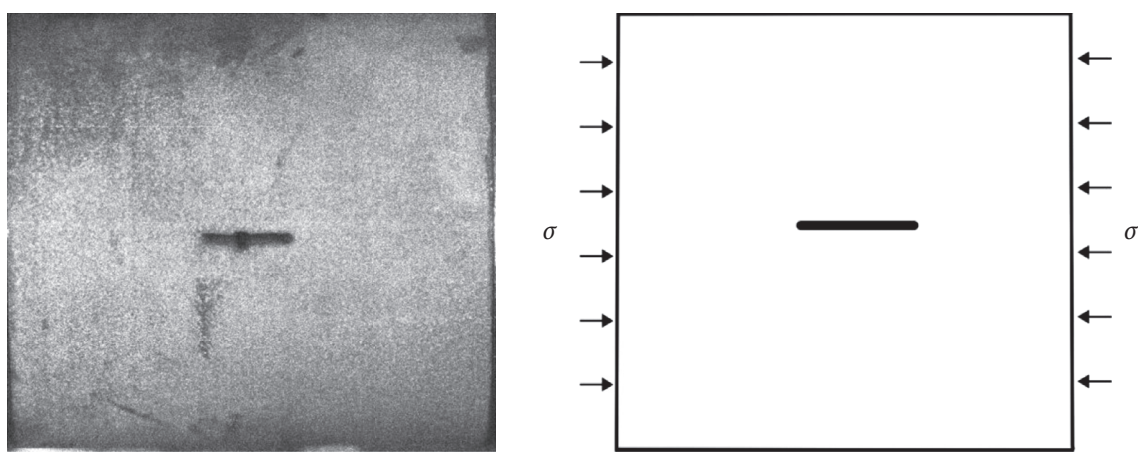

(c)

FIGURE 2: Loading methods on specimens with prefabricated fractures at (a) $0^{\circ}$, (b) $45^{\circ}$, and (c) $90^{\circ}$.

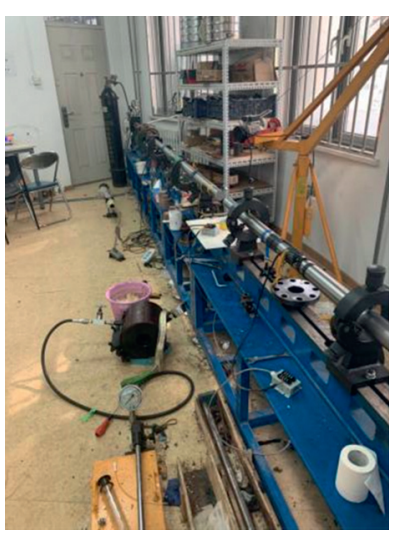

(a)

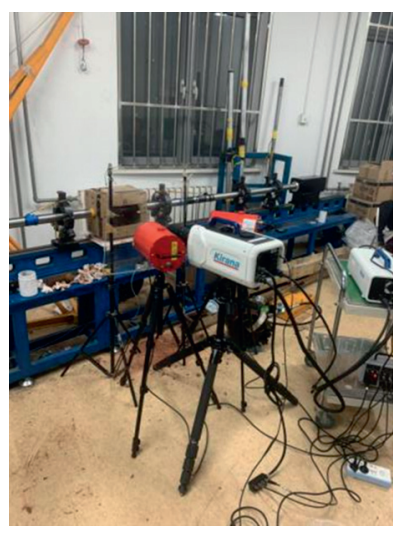

(b)

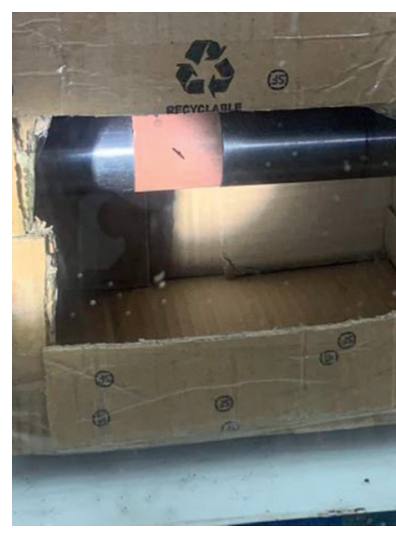

(c)

FIgURE 3: SHPB experiment rig and high-speed photography unit. 
TABLE 1: Impact velocity under different impact pressures $(\mathrm{m} / \mathrm{s})$.

\begin{tabular}{lcccc}
\hline $\begin{array}{l}\text { Impact pressure } \\
(\mathrm{MPa})\end{array}$ & $a$ & $b$ & $c$ & $\begin{array}{c}\text { Average velocity } \\
(\mathrm{m} / \mathrm{s})\end{array}$ \\
\hline 0.25 & 9.660 & 9.800 & 9.615 & 9.7 \\
0.28 & 10.716 & 10.757 & 10.430 & 10.6 \\
0.31 & 11.410 & 11.463 & 11.545 & 11.4 \\
0.34 & 12.243 & 12.255 & 12.168 & 12.2 \\
0.37 & 12.927 & 12.930 & 12.824 & 12.8 \\
\hline
\end{tabular}

and strain rate of the specimens were calculated using the two-wave method [17]. The equations of the two-wave method are expressed as follows:

$$
\begin{aligned}
\sigma(t) & =\frac{A}{A 0} E \varepsilon_{T}(t), \\
\varepsilon(t) & =-\frac{2 C}{L 0} \int_{0}^{1} \varepsilon R(t) \mathrm{dt}, \\
\dot{\varepsilon}(t) & =-\frac{2 C}{L 0} \varepsilon R(t),
\end{aligned}
$$

where $A$ is the cross-sectional area of the SHPB bar, $A_{0}$ is the cross-sectional area of a specimen; $\sigma(t)$ is the stress imposed on a specimen at the time of $t ; L_{0}$ is the length of the specimen; $\varepsilon_{T}(t)$ is the transmitted strain at the time of $t$; $\varepsilon_{R}(t)$ is the reflected strain at the time of $t$; and $C$ is the longitudinal wave velocity of the punch material.

3.2. Analysis of Fluctuation Characteristics of Stress Wave. After the impact test was completed with SHPB experimental rig, the calibration coefficient $K$ was obtained by calculation. The obtained voltage signal was converted into the strain-time waveform. The electrical signal waveforms of the three groups under different loading rates are shown in Figure 5. By analyzing the graphs, we can observe the following:

(1) The amplitude of the incident wave of the specimens with prefabricated fracture at $0^{\circ}$ increased with the loading rate, but the amplitude of the incident wave at $10.6 \mathrm{~m} / \mathrm{s}$ was slightly smaller than that at $11.4 \mathrm{~m} / \mathrm{s}$. The amplitude of the reflected wave tended to decrease then increase with the loading rate, the amplitude at $11.4 \mathrm{~m} / \mathrm{s}$ was the smallest but was basically the same at $9.7 \mathrm{~m} / \mathrm{s}$ and $12.8 \mathrm{~m} / \mathrm{s}$, and this was the maximum amplitude. The amplitude of the transmitted wave basically increased with the loading rate, and at $9.7 \mathrm{~m} / \mathrm{s}$, the rising velocity after the transmitted wave reached the valley was much slower than that at any other loading rate.

(2) The amplitude of the incident wave of the specimens with prefabricated fracture at $45^{\circ}$ reached the minimum value at $11.4 \mathrm{~m} / \mathrm{s}$, while it tended to increase with the loading rate under any other loading rate. The amplitude of the reflected wave increased and then decreased with the loading rate, and the maximum amplitude appeared at $12.2 \mathrm{~m} / \mathrm{s}$. The amplitude of the transmitted wave changed a little, and the maximum amplitude appeared at $10.6 \mathrm{~m} / \mathrm{s}$.

(3) The amplitude of the incident wave of the specimens with prefabricated fracture at $90^{\circ}$ increased with the loading rate. The amplitude of the reflected wave also increased with the loading rate; at the loading rate of $10.6 \mathrm{~m} / \mathrm{s}$, there was a tip on the curve; and the rising and falling velocity of the reflected wave was higher than that at any other rate, and the maximum amplitude appeared. The amplitude of the transmitted wave changed a little, and the maximum amplitude still appeared at $10.6 \mathrm{~m} / \mathrm{s}$. It can be inferred that the amplitude of the incident wave was positively correlated with the loading rate, and the higher loading rate means the larger amplitude of the incident wave. However, due to material nonuniformity of specimens, the test data in disconformity with the general law may occasionally occur.

It can be inferred that the amplitude of the incident wave was positively correlated with the loading rate, and the higher loading rate means the larger amplitude of the incident wave. However, due to material nonuniformity of specimens, the test data in disconformity with the general law may occasionally occur.

3.3. Dynamic Stress-Strain Relationship. All dynamic mechanical parameters of these specimens subject to the impact process were calculated using the two-wave method by the electrical signal conversion, and thus, the stress-strain curves were plotted.

Figure 6 shows the stress-strain curves of the three groups of specimens with prefabricated fractures under different loading rates. By analyzing the data, we can observe the following:

(1) The front sections of the curves for the specimens with prefabricated fracture at $0^{\circ}$ under different loading rates were close to and similar to the linear elastic working stage, indicating that the compaction stage of the specimens was completed in a short time during the loading process, which was almost impossible to observe and there was an obvious elastic deformation stage. At $9.7 \mathrm{~m} / \mathrm{s}$, the curve had no obvious plastic deformation following the elastic phase, but in direct transition from the elastic phase to the failure phase, Specimen c1 was subject to brittle failure. As the loading rate gradually increased from $10.6 \mathrm{~m} / \mathrm{s}$ to $12.8 \mathrm{~m} / \mathrm{s}$, the peak stress of the specimens with prefabricated fracture at $0^{\circ}$ increased continuously, the curve bent downward following the elastic stage, and the specimens entered the elastoplastic stage; finally, the curve began to fall, marking the failure stage; the peak stress of the specimens with prefabricated fracture at $0^{\circ}$ increased with the loading rate, and the peak stress appeared at an earlier time.

(2) For the specimens with prefabricated fracture at $45^{\circ}$ under different loading rates, the stress-strain 


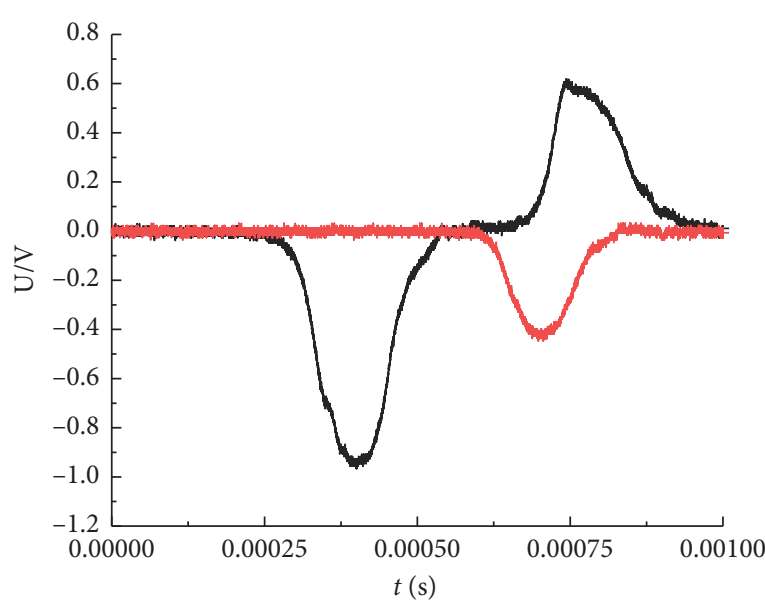

$$
\text { - in }
$$

- tra

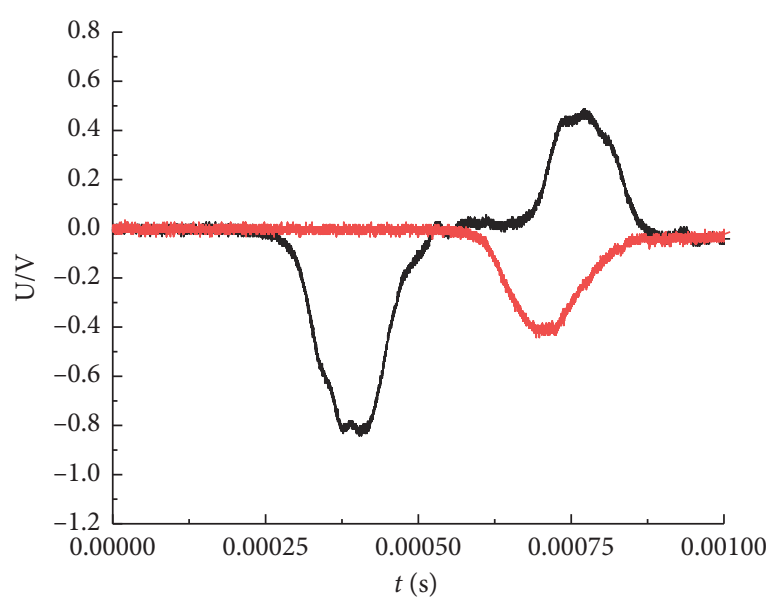

$$
\text { - in }
$$

- tra

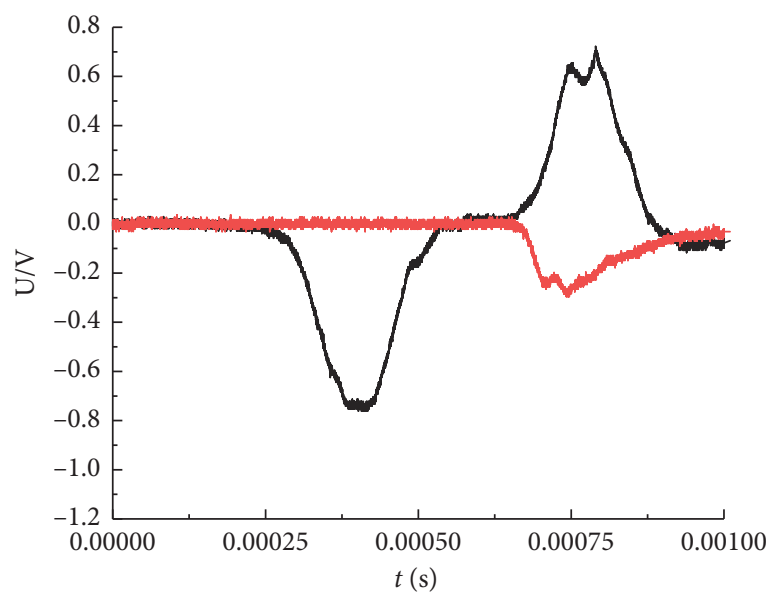

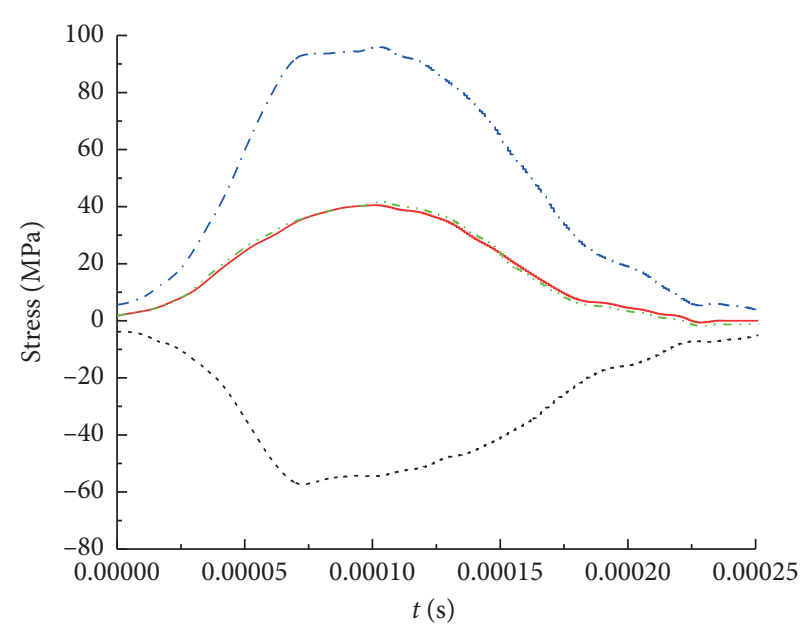

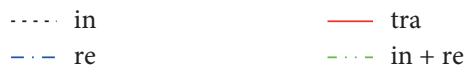

(a)
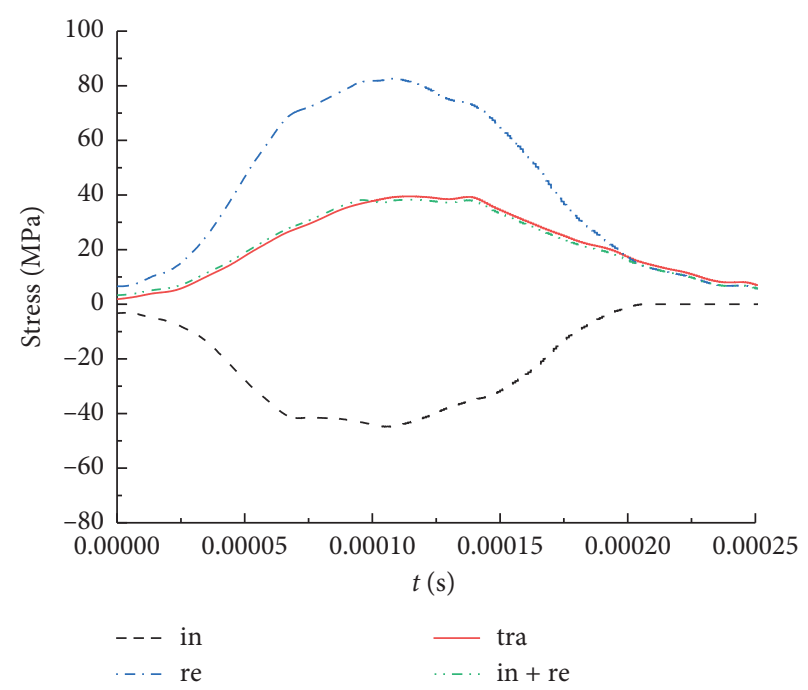

(b)
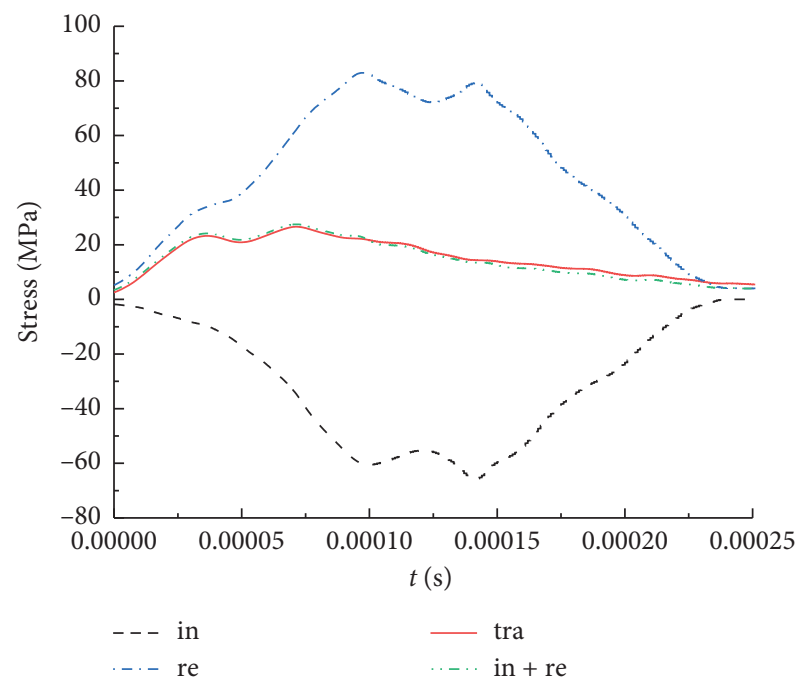

(c)

FIGURE 4: Waveform curve and stress equilibrium graph. 


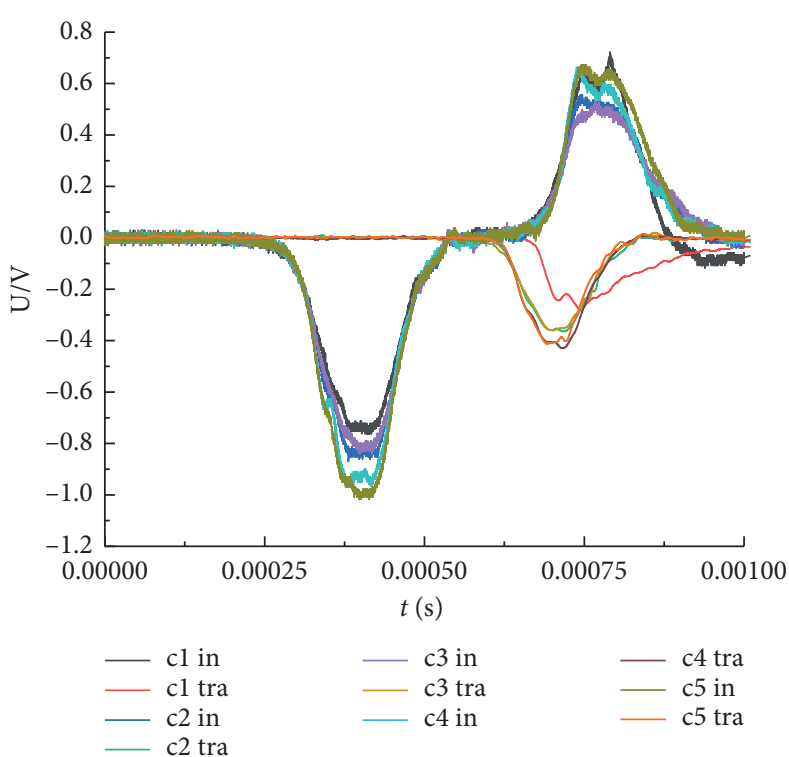

(a)

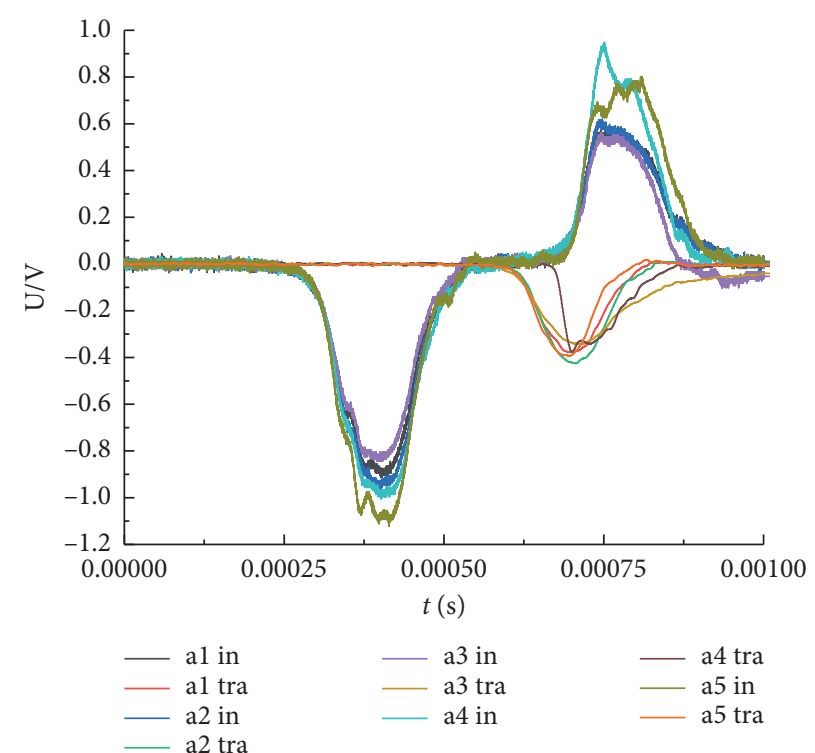

(b)

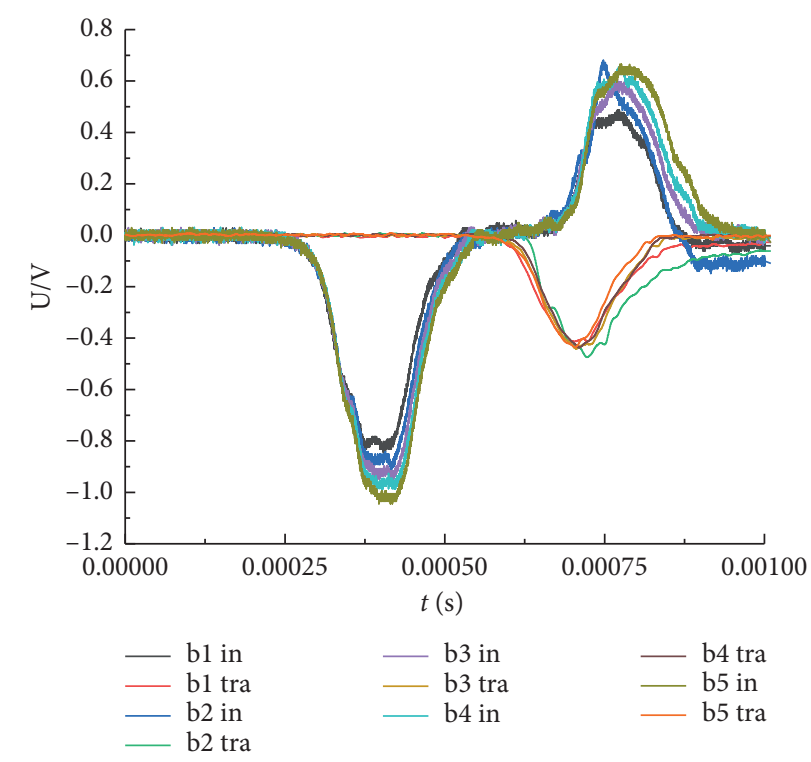

(c)

Figure 5: Waveform signal of specimens. (a) $0^{\circ}$. (b) $45^{\circ}$. (c) $90^{\circ}$.

relationship of the compaction stage phase can hardly be observed. The front sections of the curves were also close to a straight line, which was similar to the elastic working stage; at $12.2 \mathrm{~m} / \mathrm{s}$, the stress-strain curve of Specimen a4 directly began to fall and enter the failure stage after it was similar to a straight-line section, and it was considered that Specimen a4 was also subject to brittle fracture; the peak stress tended to increase then decrease and rebound at $9.7 \mathrm{~m} /$ $\mathrm{s}-12.8 \mathrm{~m} / \mathrm{s}$, the maximum value appeared at $10.6 \mathrm{~m} / \mathrm{s}$, and the minimum value appeared at $11.4 \mathrm{~m} / \mathrm{s}$. The peak stress appeared at an earlier time as the loading rate increased; following the elastic stage, the specimens with prefabricated fracture at $45^{\circ}$ also had an obvious elastoplastic stage, and they finally entered the failure stage.

(3) For the specimens with prefabricated fracture at $90^{\circ}$ under different loading rates, the stress-strain relationship of the compaction stage phase can hardly be observed as well. These specimens were also in the elastic stage, and then the curve bent downward, marking the elastoplastic stage. Finally, the descending section appeared, marking the failure stage; with the increase of the loading rate, the peak value of the specimens increased and then decreased, and the peak stress under the last three loading rates was nearly the same, but the peak stress appeared at an earlier time. 


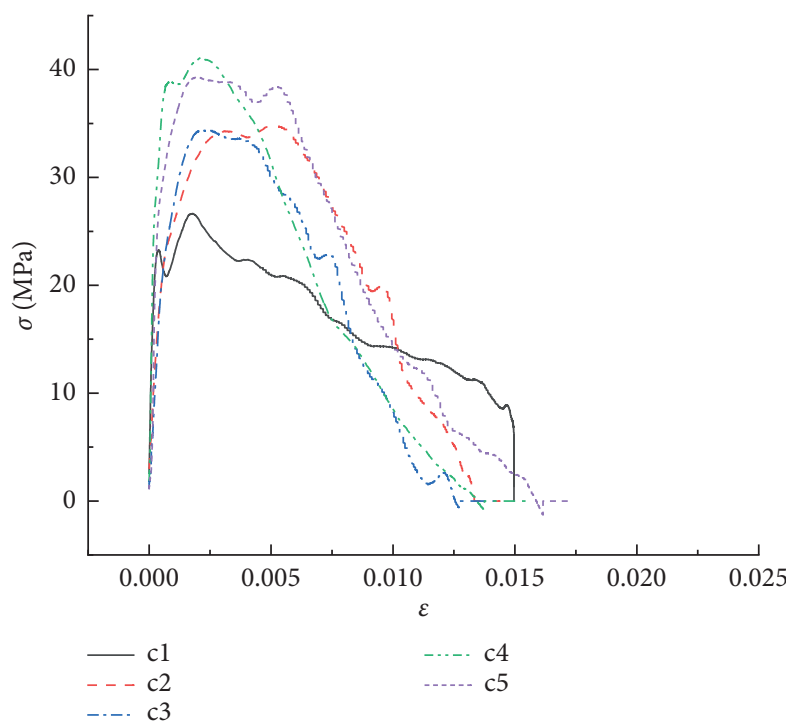

(a)

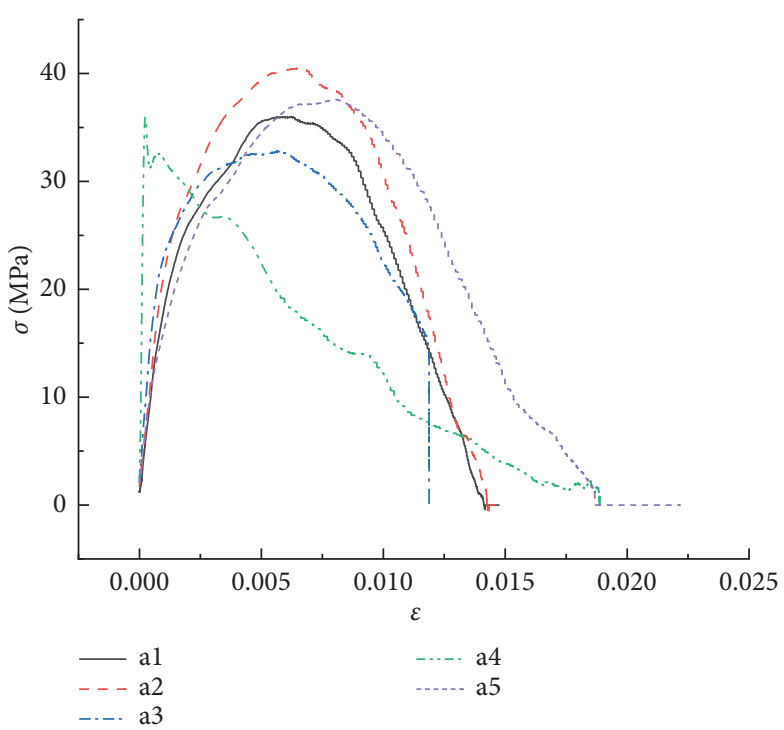

(b)

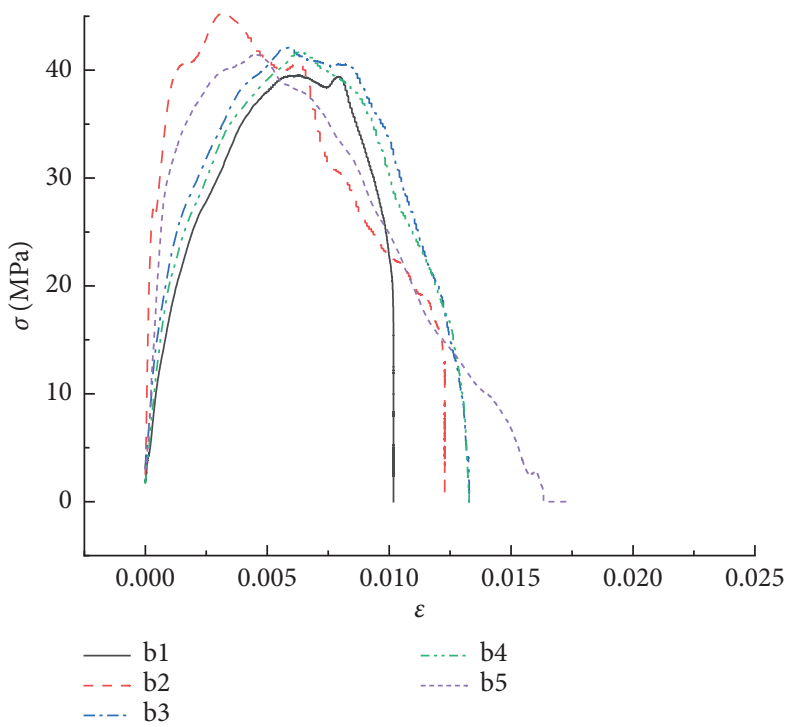

(c)

Figure 6: Stress-strain curves of specimens at different loading rates. (a) $0^{\circ}$. (b) $45^{\circ}$. (c) $90^{\circ}$.

It can be inferred that there was almost no compaction stage for the failure of specimens with three different fractures, and it was considered that there were only three stages during the impact process: the front section of the curve was similar to a straight line, and the stress-strain curve was linearly correlated. In the process, the specimens were in the linear elastic stage; then the curve bent downward, marking the elastoplastic stage; after the stress peak appeared, the curve began to fall, marking the failure stage, the fractures in the specimens continuously propagated until connected, and the stress of the specimens in the three groups slightly decreased until reached the peak, which might be caused by the material nonuniformity of specimens. With the increase of the loading rate, the stress peak of the specimens with the same fractures tended to increase and then decrease, in which the specimens with prefabricated fracture at $45^{\circ}$ and $90^{\circ}$ reached the maximum peak stress at
$9.7 \mathrm{~m} / \mathrm{s}$, and the specimens with prefabricated fracture at $0^{\circ}$ reached the maximum peak stress at $12.2 \mathrm{~m} / \mathrm{s}$.

\subsection{Dynamic Mechanical Parameters}

3.4.1. Relationship between Dynamic Compressive Strength and Loading Rate, Prefabricated Fracture Angle, and Strain Rate. According to the calculation of dynamic compressive strength $[19,20]$, the relationship between dynamic compressive strength and loading rate for the three groups of specimens with prefabricated fractures is shown in Figure 7(a). By analyzing the test data, we can observe the following.

The dynamic compressive strength of the specimens with prefabricated fracture at $0^{\circ}$ increased and then decreased with the loading rate, which was similar at $10.6 \mathrm{~m} / \mathrm{s}$ and 


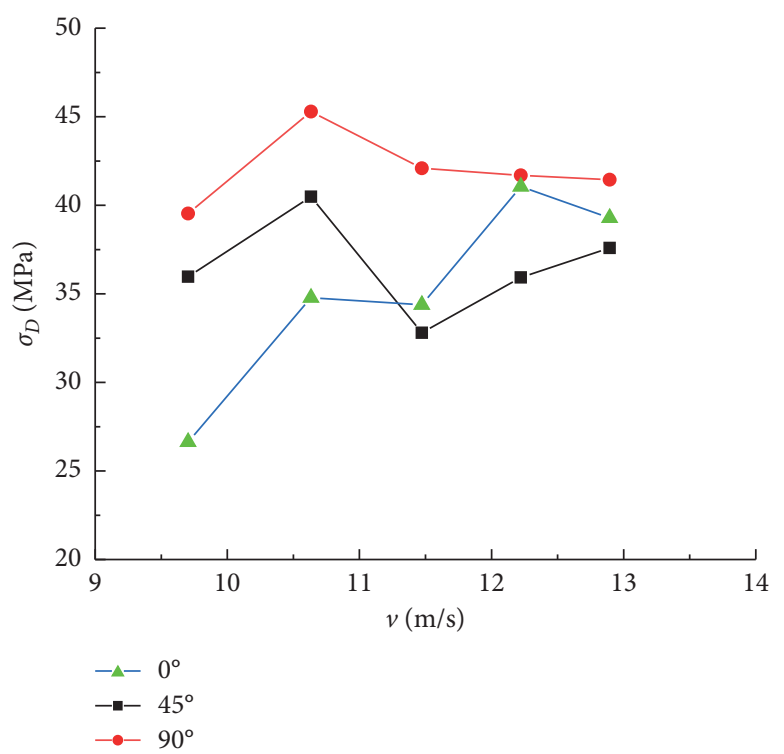

(a)

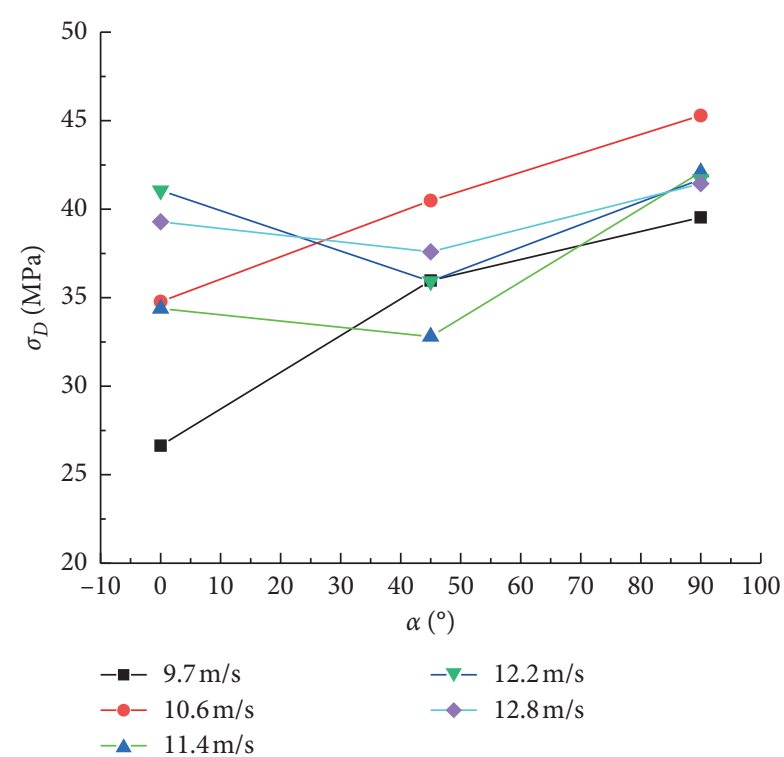

(b)

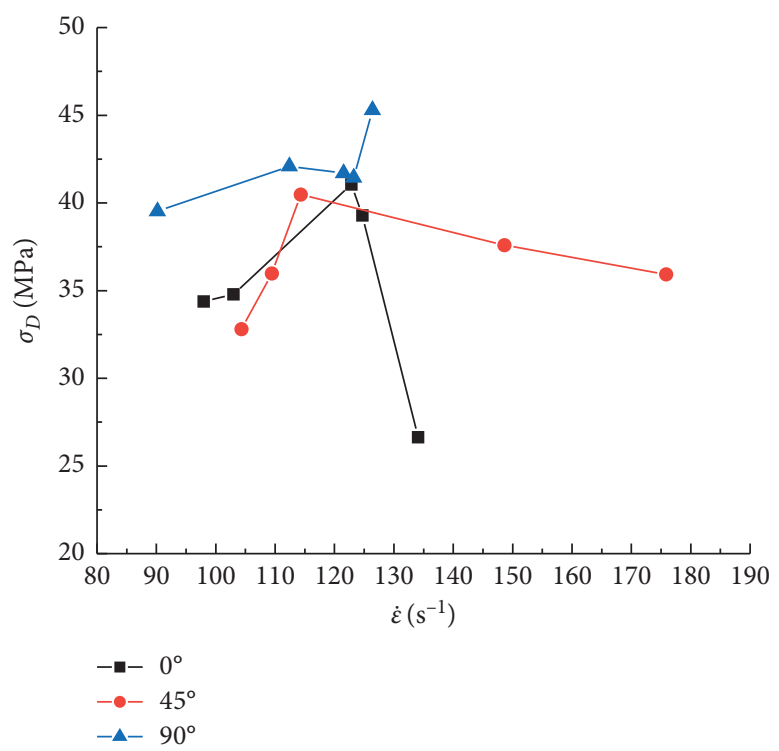

(c)

FIgURE 7: Relationship curves between dynamic compressive strength and loading rate, prefabricated fracture angle, and strain rate.

$11.4 \mathrm{~m} / \mathrm{s}$, and the maximum value appeared at $12.2 \mathrm{~m} / \mathrm{s}$. The dynamic compressive strength of the specimens with prefabricated fracture at $45^{\circ}$ tended to increase, then decrease, and increase with the loading rate, and the maximum value appeared at $10.7 \mathrm{~m} / \mathrm{s}$, and the minimum value appeared at $11.4 \mathrm{~m} / \mathrm{s}$. The dynamic compressive strength of the specimens with prefabricated fracture at $90^{\circ}$ tended to increase and then decrease with the loading rate, and the maximum value was also reached at $10.7 \mathrm{~m} / \mathrm{s}$. It can be inferred that the dynamic compressive strength of the specimens generally tended to increase and then decrease with the loading rate.

Under the same loading rate, the relationship between the dynamic compressive strength and the prefabricated fracture angle of the three groups of specimens with prefabricated fracture is shown in Figure 7(b). By analyzing the test data, we can see that at $9.7 \mathrm{~m} / \mathrm{s}$ and $10.6 \mathrm{~m} / \mathrm{s}$, the $d y$ namic compressive strength of the specimens increased with the prefabricated fracture angle; at $11.4 \mathrm{~m} / \mathrm{s}, 12.2 \mathrm{~m} / \mathrm{s}$, and $12.8 \mathrm{~m}$, the dynamic compressive strength of the specimens tended to increase and then decrease with the prefabricated fracture angle.

Strain rate means the change of material strain (deformation) related to time $[17,18]$. The strain rate as referred to in this paper is the strain change of the sandstone specimens with prefabricated fracture related to time, the strain rate curves were calculated using the two-wave method, and the peak value of the strain rate curves was considered as the strain rate for this group of specimens. The relationship between dynamic compressive strength and strain rate is shown in Figure 7(c). The dynamic compressive strength of 
the specimens with prefabricated fracture at $0^{\circ}$ and $45^{\circ}$ increased and then decreased with the strain rate, the falling velocity of the specimens with prefabricated fracture at $45^{\circ}$ was much higher than that with prefabricated fracture at $0^{\circ}$, the dynamic compressive strength of the specimens with prefabricated fracture at $90^{\circ}$ tended to increase and decrease and then rebound with the strain rate, and the dynamic compressive strength of the specimens with prefabricated fracture at $0^{\circ}$ and $90^{\circ}$ generally tended to increase because the specimens with prefabricated fracture at $45^{\circ}$ were subject to the material nonuniformity of the specimens under test at $134 \mathrm{~s}^{-1}$, so it can be eliminated here. It can be inferred that the dynamic compressive strength of the specimens was linearly correlated with the strain rate and tended to increase with the strain rate.

3.4.2. Relationship between Peak Strain and Loading Rate, Prefabricated Fracture Angle, and Strain Rate. Peak strain was the maximum dynamic strain calculated by the twowave method through impact test of the specimens. The relationship between peak strain and loading rate is shown in Figure 8(a). As is shown from Figure 8(a), the peak strains of the specimens with prefabricated fracture at $0^{\circ}$ basically had no change at $9.7 \mathrm{~m} / \mathrm{s}, 10.6 \mathrm{~m} / \mathrm{s}$, and $11.4 \mathrm{~m} / \mathrm{s}$, followed by a gradual increase; the peak strains of the specimens with prefabricated fracture at $45^{\circ}$ were basically the same at $9.7 \mathrm{~m} / \mathrm{s}$ and $10.6 \mathrm{~m} / \mathrm{s}$. After that, as the loading rate increased, the peak strain gradually increased, and the rising velocity was higher than that of the specimens with prefabricated fracture at $0^{\circ}$ and $90^{\circ}$, respectively; the peak strain of the specimens with prefabricated fracture at $90^{\circ}$ continuously increased from $9.7 \mathrm{~m} / \mathrm{s}$ to $12.8 \mathrm{~m} / \mathrm{s}$, and the rising amplitude was slightly higher than that of the specimens with prefabricated fracture at $0^{\circ}$. It can be inferred that the peak strain of the specimens would increase with the loading rate.

The relationship between peak strain and prefabricated crack angle is shown in Figure $8(\mathrm{~b})$. At the loading rate of $9.7 \mathrm{~m} / \mathrm{s}$ and $10.6 \mathrm{~m} / \mathrm{s}$, the peak strains of the specimens with prefabricated fracture at $0^{\circ}$ and $45^{\circ}$ were basically the same; in the specimens with prefabricated fracture at $45^{\circ}$ and $90^{\circ}$, the peak strain decreased as the angle increased, and the falling velocity of the peak strain at $9.7 \mathrm{~m} / \mathrm{s}$ was higher than that at $10.6 \mathrm{~m} / \mathrm{s}$; at the loading rate of $11.4 \mathrm{~m} / \mathrm{s}, 12.2 \mathrm{~m} / \mathrm{s}$, and $12.8 \mathrm{~m} / \mathrm{s}$, the peak strains of the specimens tended to increase and then decrease with the angle. It can be inferred that the overall peak strain of the specimens tended to increase and then decrease with the prefabricated fracture angle.

The relationship between peak strain and strain rate is shown in Figure 8(c). The peak strains of the specimens with prefabricated fracture at $0^{\circ}$ and $90^{\circ}$ increased and then decreased with the strain rate; the peak strain of the specimens with prefabricated fracture at $45^{\circ}$ decreased, increased, and then decreased with the strain rate, and the overall peak strain tended to increase.

3.4.3. Relationship between Dynamic Elastic Modulus and Loading Rate, Prefabricated Fracture Angle, and Strain Rate.
Dynamic elastic modulus was the tangent slope of the front end of the stress-strain curves approximated to a straight line section [19], namely, the tangent modulus. In this paper, the tangent line of the stress-strain curve plotted by Tangent in origin 2017 for the elastic stage of the specimens was used to obtain its tangent slope, namely, the dynamic elastic modulus of the specimens.

The relationship between dynamic elastic modulus and loading rate is shown in Figure 9(a). The dynamic elastic modulus of the specimens with prefabricated fracture at $0^{\circ}$ increased, then decreased, and finally increased again with the loading rate, the minimum dynamic elastic modulus appeared at $10.7 \mathrm{~m} / \mathrm{s}$, and the maximum dynamic elastic modulus appeared at $12.2 \mathrm{~m} / \mathrm{s}$. The dynamic elastic modulus of the specimens with prefabricated fracture at $45^{\circ}$ tended to repeatedly fluctuate, and the amplitude of fluctuation increased with the loading rate. The dynamic elastic modulus at $12.2 \mathrm{~m} / \mathrm{s}$ was much higher than that at any other loading rate, which may be subject to the material of specimens. The dynamic elastic modulus of the specimens with prefabricated fracture at $90^{\circ}$ also fluctuated with the loading rate and generally tended to rise.

The relationship between dynamic elastic modulus and prefabricated fracture angle is shown in Figure 9(b). As is shown from Figure $9(\mathrm{~b})$, at $9.7 \mathrm{~m} / \mathrm{s}$, the dynamic elastic modulus of the specimens always decreased with the prefabricated fracture angle, and the dynamic elastic modulus of the specimens with prefabricated fracture angle at $45^{\circ}$ and $90^{\circ}$ was similar; the dynamic elastic modulus of the specimens with prefabricated fracture angle at $0^{\circ}$ and $90^{\circ}$ was almost equal. Under all loading rates, the dynamic elastic modulus tended to decrease and then increase with the prefabricated crack angle.

The relationship between dynamic elastic modulus and strain rate is shown in Figure $9(\mathrm{c})$. As is shown from Figure 9(c), the dynamic elastic modulus of the specimens with prefabricated fracture at $0^{\circ}$ decreased and then increased with the strain rate, the minimum dynamic elastic modulus appeared at $102.99 \mathrm{~s}^{-1}$, and the maximum dynamic elastic modulus appeared at $122.84 \mathrm{~s}^{-1}$; the dynamic elastic modulus of the specimens with prefabricated fracture at $45^{\circ}$ tended to increase, then decrease, and finally increase with the strain rate, the minimum dynamic elastic modulus appeared at $175.87 \mathrm{~s}^{-1}$, and the maximum dynamic elastic modulus appeared at $148.64 \mathrm{~s}^{-1}$; the images of the specimens with prefabricated fracture at $90^{\circ}$ and $0^{\circ}$ were similar, from $90.2 \mathrm{~s}^{-1}$ to $112.38 \mathrm{~s}^{-1}$, the dynamic elastic modulus almost stayed the same and increased then decreased with the strain rate. It can be inferred that the dynamic elastic modulus of the specimens increased with the strain rate, but it would fluctuate due to the effects of anisotropy and nonuniformity of the specimens.

3.5. Dynamic Crack Propagation Process. The dynamic fracture process of the specimens during the impact load was recorded by using a high-speed photography unit, and the crack propagation development of the three groups of specimens was obtained. In this paper, the high-speed 


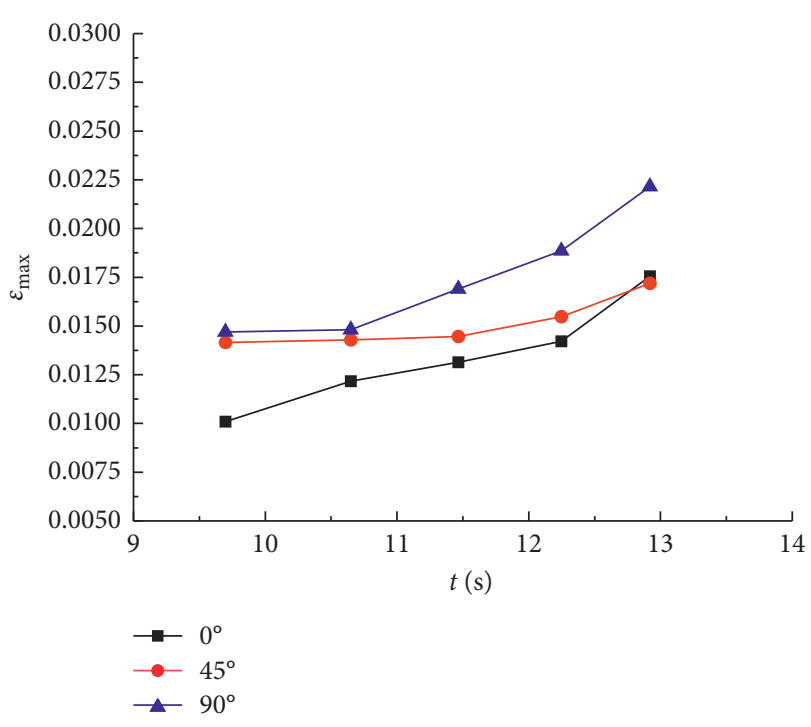

(a)

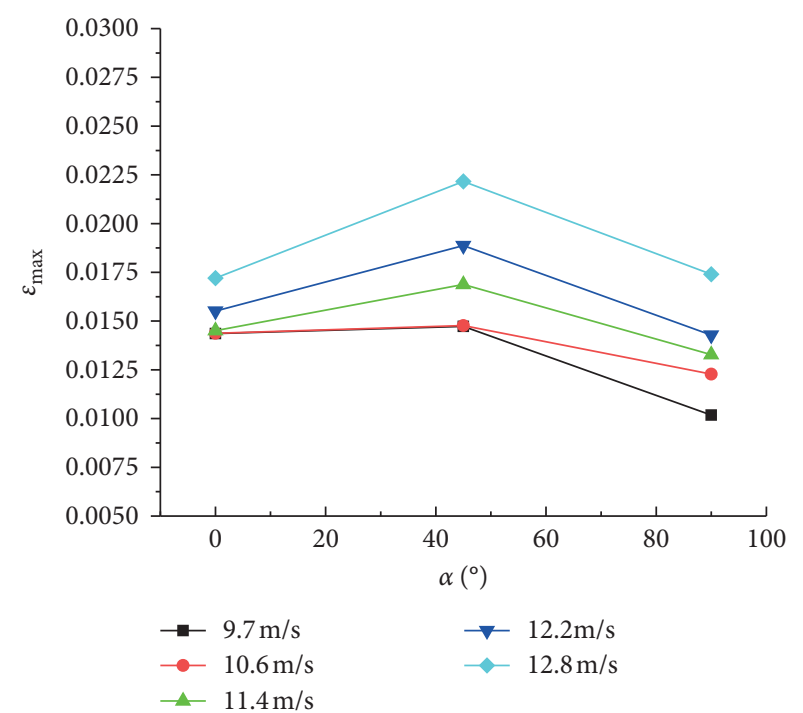

(b)

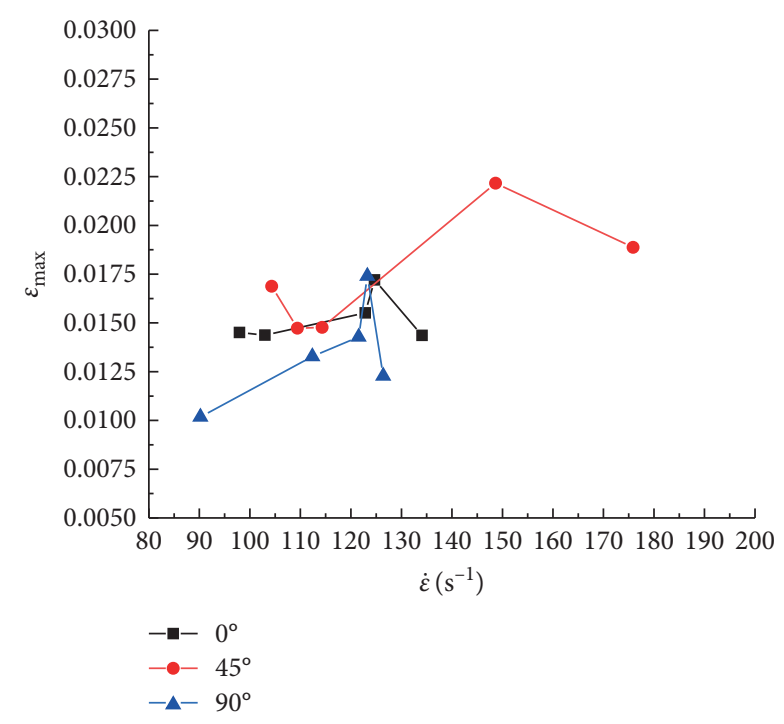

(c)

FIGURE 8: Relationship between peak strain and loading rate, prefabricated fracture angle, and strain rate.

images for the damaged specimens of 6 typical specimens at three timing points (before the stress peak, at the stress peak, and after the stress peak) were selected and presented. Tables 2 and 3 show the crack propagation process of the sandstone specimens with prefabricated fracture at $0^{\circ}(\mathrm{c} 1$, c3); Tables 4 and 5 show the crack propagation process of the sandstone specimens with prefabricated fracture at $45^{\circ}$ (a1, a2); Tables 6 and 7 show the crack propagation process of the sandstone specimens with prefabricated fracture at $90^{\circ}(\mathrm{b} 2$, b3). As given in these tables, the thicker the crack sketch line is, the larger the crack will be. For more details, refer Tables 2-7.

As is shown from Tables 2-7, the shear failure and tensile failure occurred during the dynamic loading process, and almost all cracks began to propagate from the vertex of the prefabricated fracture, the shear failure dominated until the peak stress appeared. After the peak stress, the specimens were subjected to shear failure and obvious tensile failure. For the specimens with prefabricated fracture at $0^{\circ}$ and $45^{\circ}$, of all failures occurred after the stress peak, the cracks subject to tensile failure tended to be more obvious; for the specimens with prefabricated fracture at $90^{\circ}$, the number of cracks caused due to shear failure was much more than that due to tensile failure. Main connected cracks of the specimens with prefabricated fracture at $0^{\circ}$ and $45^{\circ}$ were formed subject to shear and tension, while those of the specimens with prefabricated fracture at $90^{\circ}$ were mainly subject to shear effect and were subject to almost no tension effect. Two end faces of the specimens were subject to stress concentration, and cracks initiated from the end faces after the main connected cracks occurred. For Specimens b2 and b3 with prefabricated fracture at $90^{\circ}$ and Specimen c1 with prefabricated fracture at $0^{\circ}$, cracks initiated from the middle of the fracture. As is seen from the images of specimens, 


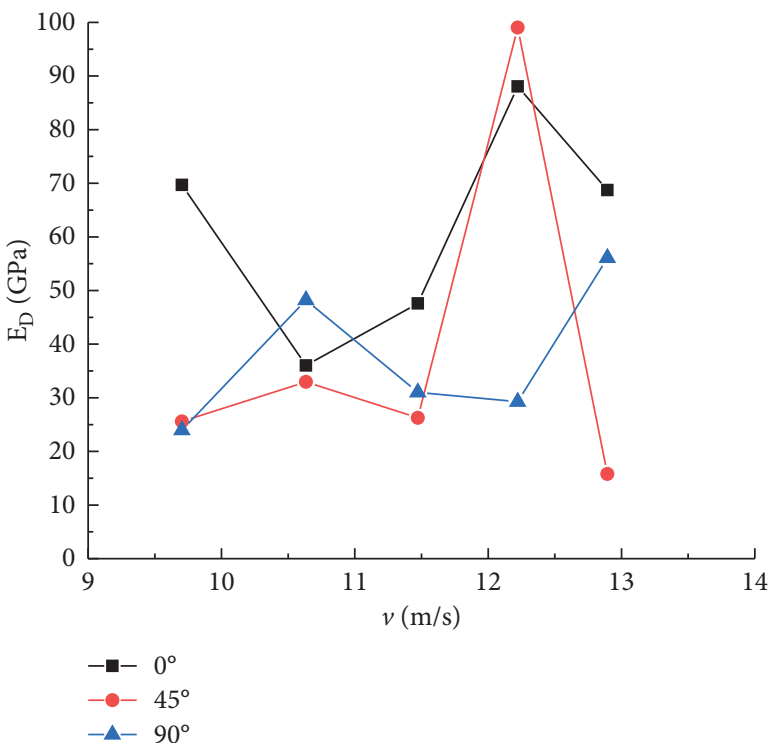

(a)

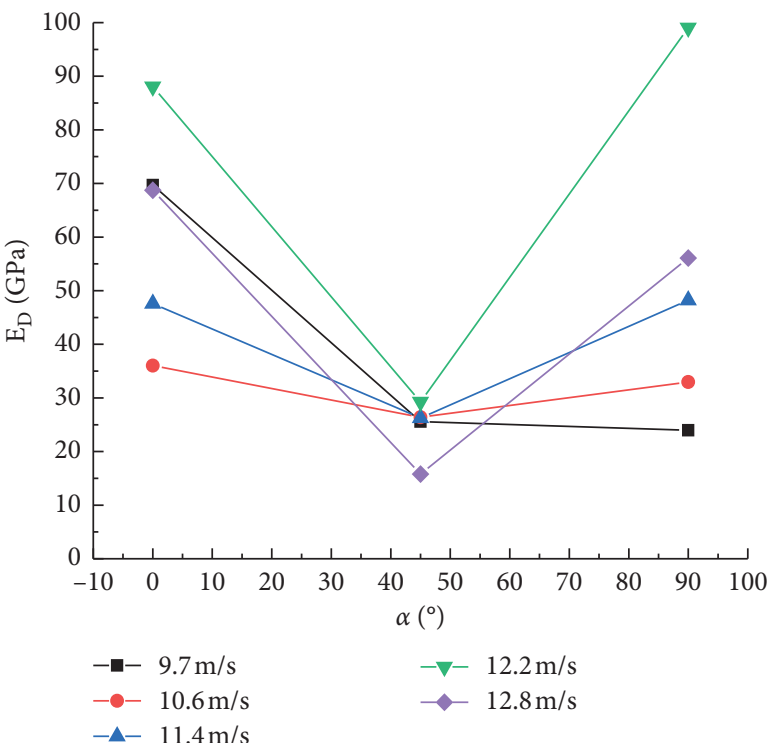

(b)

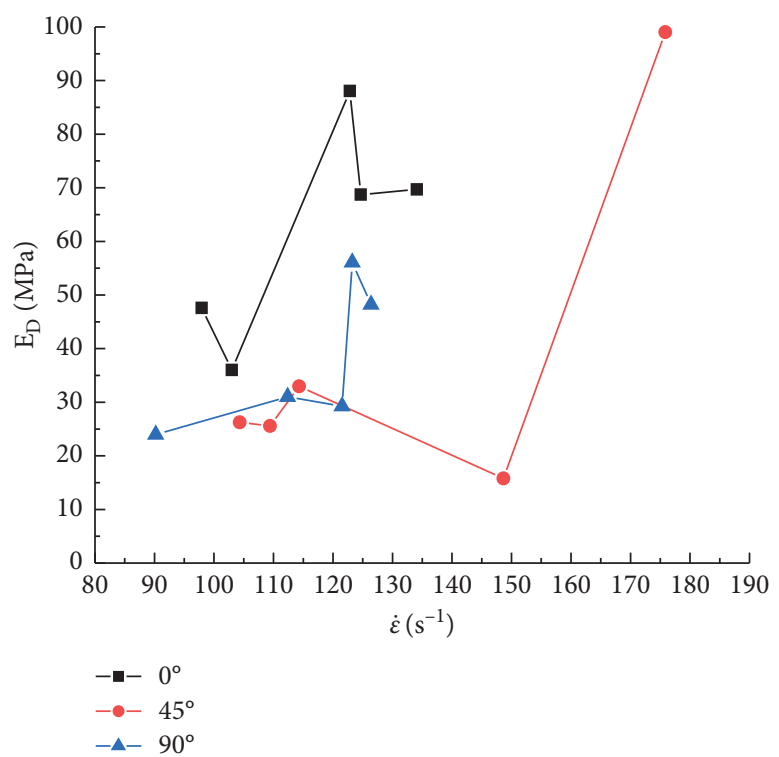

(c)

FIgURE 9: Relationship curves between dynamic elastic modulus and loading rate, prefabricated fracture angle, and strain rate.

there was an obvious hole in the middle of prefabricated fractures of the three specimens. A possible reason is that the hole was subject to the highest force during the impact process due to the effect of point, and consequently, a crack initiated from the hole and this became the main connected crack during the dynamic impact. Provided that the prefabricated fracture was the same, the primary crack propagation modes of the specimens were basically the same, the velocity of the primary crack propagation increased with the loading rate; provided that the loading rate was the same, the crack propagation of the specimens increased with the prefabricated fracture angle, the primary crack formed subject to shear, and tension transited to the shear splitting.
3.6. Final Failure Mode of the Specimens. The specimens were completely damaged after being impacted by the SHPB experimental rig. According to the law of crack propagation derived from Section 3.5, it can be inferred that the crack propagation mode of the specimens was only related to the prefabricated fracture angle of the specimens. In this section, the final failure mode of a specimen was selected from each group of the specimens with different prefabricated fracture was discussed, and the final failure mode of the three specimens is shown in Figure 10. As is seen from Figure 10, the primary crack on the specimens with prefabricated fracture at $0^{\circ}, 45^{\circ}$, and $90^{\circ}$ propagated from the tip end of prefabricated fracture to the ends of the specimens until fully connected, the crack formed in this manner had the largest 
TABLE 2: Crack propagation process of Specimen $\mathrm{cl}$ at the loading rate of $9.7 \mathrm{~m} / \mathrm{s}$.

\begin{tabular}{|c|c|c|c|c|}
\hline High-speed images & Crack sketch & Stress $(\mathrm{MPa})$ & Loading time $(\mu \mathrm{s})$ & Crack propagation process \\
\hline & & $\begin{array}{c}20.82 \\
\text { Prepeak }\end{array}$ & 27.9 & $\begin{array}{l}\text { Cracks began to occur from the middle } \\
\text { of prefabricated fracture of the specimen }\end{array}$ \\
\hline & & $\begin{array}{l}26.44 \\
\text { At peak }\end{array}$ & 71.9 & Cracks continued to propagate \\
\hline & 1 & $\begin{array}{c}17.44 \\
\text { Postpeak }\end{array}$ & 123.7 & $\begin{array}{l}\text { Cracks propagating from the middle of fracture } \\
\text { extended and connected through the entire } \\
\text { specimen, with increasing width of cracks }\end{array}$ \\
\hline
\end{tabular}

width of all photographed specimen surfaces, and the finally failed cracks were composed of the cracks formed subject to the combined action of shear and tension, in which the cracks formed subject to shear dominating, and all specimen surfaces were found with the cracks propagated from the left and right-end faces. It can be inferred that as the load began to act on the surface, the stress at the tip end of prefabricated fracture may be slightly smaller than the fore on the end face of the specimen due to loading and cracks would initiate along the direction of prefabricated fracture and from the left and right-end faces of the specimen. When the stress at the tip end of the fracture reached a certain value, the primary crack of the specimen initiated and propagated, and the cracks formed from the fracture and the end faces of the specimen continuously propagated. The finally formed main connected crack and the cracks formed in parallel with the direction of loading constituted the final failure mode of the specimens.

3.7. Crack Initiation Angle and Initiation Stress. The smaller of the angles between the initiated crack of the primary crack and the prefabricated fracture angle was referred to as crack initiation angle $\theta$, and the crack initiation angles for the specimen with prefabricated fracture at $0^{\circ}, 45^{\circ}$, and $90^{\circ}$ are shown in Figure 11. The measured values of the crack initiation angle are given in Table 8.

The crack initiation stress of rock is one of the important grounds for judging whether the rock is subject to fracture or not. Crack initiation stress means that the stress applied on the specimen when the macrocrack begins to form, and Gaziev and Levtchouk [21, 22] and Huang et al. [23] examined the relationship between crack initiation stress and rock damage energy and the relationship between crack initiation stress and loading rate. The crack initiation stress obtained by calculation [17-21] is given in Table 9.

3.7.1. Relationship between Crack Initiation Angle and Loading Rate, Prefabricated Fracture Angle, and Strain Rate. The relationship between crack initiation angle and loading rate is shown in Figure 12(a). As is shown from Figure 12(a), the crack initiation angle of the specimen with prefabricated fracture at $0^{\circ}$ decreased, and then increased and finally decreased with the loading rate, and the minimum initiation angle $\left(65^{\circ}\right)$ appeared at $11.4 \mathrm{~m} / \mathrm{s}$, but the crack initiation angles of the other four loading rates fluctuated around $90^{\circ}$, but such difference was not obvious; the crack initiation angle of the specimen with prefabricated fracture at $45^{\circ}$ tended to decrease and increase and then decrease with the loading rate, and the minimum initiation angle $\left(35^{\circ}\right)$ appeared at $10.6 \mathrm{~m} / \mathrm{s}$, but the crack initiation angles of the other four loading rates fluctuated around $60^{\circ}$, and the amplitude of fluctuation was about $5^{\circ}$; the crack initiation angle of the specimen with prefabricated fracture at $90^{\circ}$ fluctuated with the loading rate and gradually decreased with the loading rate. It can be inferred that the crack initiation angle of the specimen basically did not change with the loading rate. Similarly, subject to the nonuniformity of the specimen, the crack initiation angle fluctuated around a certain value. According to the analysis as described in Section 3.5, a part of crack initiation angles on the specimen with prefabricated fracture at $90^{\circ}$ propagated from the middle of prefabricated fracture, leading to a widened difference of experimental data.

The relationship between crack initiation angle and prefabricated fracture angle is shown in Figure 12(b). As is seen from Figure 12(b), under all loading rates, the crack initiation angle of the specimens decreased with the prefabricated fracture angle. According to the crack initiation sketch as shown in Section 3.7, it can be inferred that the crack initiated from the tip of prefabricated fracture because the specimen was subject to the dynamic load in the horizontal direction, and the stress concentration on the fracture tip along the horizontal direction was larger. As the prefabricated fracture angle of the specimens increased, the angle between the horizontal stress and the prefabricated fracture angle decreased, so the crack initiation angle decreased with the prefabricated fracture angle.

The relationship between the crack initiation angle and the strain rate is shown in Figure 12(c). The crack initiation angle of the specimen with prefabricated fracture at $0^{\circ}$ 
TABLE 3: Crack propagation process of Specimen c3 at the loading rate of $11.4 \mathrm{~m} / \mathrm{s}$.

\begin{tabular}{|c|c|c|c|c|}
\hline $\begin{array}{l}\text { High-speed } \\
\text { images }\end{array}$ & Crack sketch & $\begin{array}{l}\text { Stress } \\
(\mathrm{MPa})\end{array}$ & $\begin{array}{l}\text { Loading time } \\
(\mu \mathrm{s})\end{array}$ & Crack propagation process \\
\hline & & $\begin{array}{c}26.74 \\
\text { Prepeak }\end{array}$ & 52.6 & $\begin{array}{c}\text { Cracks propagating to the left and right directions occurred from the vertex } \\
\text { of the prefabricated fracture of specimen }\end{array}$ \\
\hline & & $\begin{array}{c}34.38 \\
\text { At peak }\end{array}$ & 101.2 & $\begin{array}{l}\text { Cracks further propagated to two ends, and cracks occurred on the right-end } \\
\text { face of the specimen }\end{array}$ \\
\hline & & $\begin{array}{c}23.73 \\
\text { Postpeak }\end{array}$ & 121.0 & $\begin{array}{l}\text { Cracks propagating from the vertex of the fracture had increased width and } \\
\text { connected through the specimen, and cracks covered up the two end faces of } \\
\text { the specimen }\end{array}$ \\
\hline
\end{tabular}

TABle 4: Crack propagation process of Specimen a1 at the loading rate of $19.7 \mathrm{~m} / \mathrm{s}$.

\begin{tabular}{|c|c|c|c|c|}
\hline $\begin{array}{l}\text { High-speed } \\
\text { images }\end{array}$ & Crack sketch & $\begin{array}{l}\text { Stress } \\
(\mathrm{MPa})\end{array}$ & $\begin{array}{l}\text { Loading time } \\
(\mu \mathrm{s})\end{array}$ & Crack propagation process \\
\hline & & $\begin{array}{c}28.00 \\
\text { Prepeak }\end{array}$ & 70.5 & $\begin{array}{l}\text { White spots began to occur from the vertex of the prefabricated fracture of } \\
\text { specimen, and microcracks occurred locally }\end{array}$ \\
\hline & & $\begin{array}{l}35.97 \\
\text { At peak }\end{array}$ & 106.4 & $\begin{array}{l}\text { Cracks continued to propagate, and cracks gradually occurred from the ends } \\
\text { of specimen }\end{array}$ \\
\hline & & $\begin{array}{c}24.67 \\
\text { Postpeak }\end{array}$ & 147.0 & $\begin{array}{l}\text { More cracks occurred from the ends of the specimen, and cracks } \\
\text { propagating from the vertex of the prefabricated fracture had increased } \\
\text { width }\end{array}$ \\
\hline
\end{tabular}

TABle 5: Crack propagation process of Specimen a2 at the loading rate of $10.6 \mathrm{~m} / \mathrm{s}$.

\begin{tabular}{|c|c|c|c|c|}
\hline $\begin{array}{l}\text { High-speed } \\
\text { images }\end{array}$ & Crack sketch & $\begin{array}{l}\text { Stress } \\
(\mathrm{MPa})\end{array}$ & $\begin{array}{c}\text { Loading time } \\
(\mu \mathrm{s})\end{array}$ & Crack propagation process \\
\hline & & $\begin{array}{c}33.64 \\
\text { Prepeak }\end{array}$ & 68.0 & $\begin{array}{l}\text { Microcracks occurred from the vertex of prefabricated fracture of the } \\
\text { specimen }\end{array}$ \\
\hline & & $\begin{array}{l}40.48 \\
\text { At peak }\end{array}$ & 102.3 & $\begin{array}{l}\text { Cracks occurred at the vertex of specimen fracture propagated from left to } \\
\text { right, leading to a few of branching cracks }\end{array}$ \\
\hline & & $\begin{array}{c}30.26 \\
\text { Postpeak }\end{array}$ & 137.6 & $\begin{array}{l}\text { Cracks gradually propagated with increased width, and cracks began to } \\
\text { occur at the ends of the specimen }\end{array}$ \\
\hline
\end{tabular}


TABLE 6: Crack propagation process of Specimen b2 at the loading rate of $10.6 \mathrm{~m} / \mathrm{s}$.

\begin{tabular}{|c|c|c|c|c|}
\hline $\begin{array}{l}\text { High-speed } \\
\text { images }\end{array}$ & Crack sketch & $\begin{array}{l}\text { Stress } \\
(\mathrm{MPa})\end{array}$ & $\begin{array}{l}\text { Loading time } \\
\qquad(\mu \mathrm{s})\end{array}$ & Crack propagation process \\
\hline$\rightarrow$ & - & $\begin{array}{c}33.155 \\
\text { Prepeak }\end{array}$ & 51.0 & $\begin{array}{l}\text { Microcracks propagating to the lower left part and then to the upper right } \\
\text { part occurring from the middle of prefabricated fracture of the specimen }\end{array}$ \\
\hline & $\rightarrow$ & $\begin{array}{l}45.27 \\
\text { At peak }\end{array}$ & 116.3 & $\begin{array}{l}\text { Cracks continued to propagate from the middle of fracture to the right } \\
\text { direction }\end{array}$ \\
\hline & 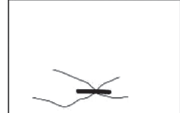 & $\begin{array}{c}32.35 \\
\text { Postpeak }\end{array}$ & 162.6 & Cracks continued to propagate with increased width \\
\hline
\end{tabular}

TABLE 7: Crack propagation process of Specimen b3 at the loading rate of $11.4 \mathrm{~m} / \mathrm{s}$.

\begin{tabular}{|c|c|c|c|c|}
\hline $\begin{array}{c}\text { High-speed } \\
\text { images }\end{array}$ & Crack sketch & $\begin{array}{l}\text { Stress } \\
(\mathrm{MPa})\end{array}$ & $\begin{array}{l}\text { Loading time } \\
(\mu \mathrm{s})\end{array}$ & Crack propagation process \\
\hline & & $\begin{array}{c}34.18 \\
\text { Prepeak }\end{array}$ & 69.8 & $\begin{array}{l}\text { Microcracks propagating to the left and right directions occurred from the } \\
\text { vertex of the prefabricated fracture of specimen }\end{array}$ \\
\hline & & $\begin{array}{l}42.09 \\
\text { At peak }\end{array}$ & 104.4 & $\begin{array}{c}\text { Cracks began to occur from the middle of the specimen fracture, and cracks } \\
\text { began to occur near the left-end face }\end{array}$ \\
\hline & & $\begin{array}{c}33.68 \\
\text { Postpeak }\end{array}$ & 139.3 & $\begin{array}{l}\text { Cracks continued to propagate with increased width, and more cracks } \\
\text { covered up the surface of the specimen }\end{array}$ \\
\hline
\end{tabular}

continuously increased with the strain rate, and there was a slight falling at $122.84 \mathrm{~s}^{-1}$ and $124.67 \mathrm{~s}^{-1}$, which generally tended to rise with the strain rate; the crack initiation angle of the specimen with prefabricated fracture at $45^{\circ}$ tended to decrease and then increase with the strain rate; the crack initiation angle of the specimen with prefabricated fracture at $90^{\circ}$ fluctuated sharply as the strain rate increased, rose, and fell continuously, and the smaller crack initiation angles appeared at $112.38 \mathrm{~s}^{-1}$ and $123.24 \mathrm{~s}^{-1}$. The cracks in these two groups initiated from the middle of prefabricated fracture, with the exclusion of these two groups, and the crack initiation angle of the specimen with prefabricated fracture at $90^{\circ}$ increased with the strain rate. It can be inferred that the crack initiation angle of the specimens tended to increase with the stain rate.

3.7.2. Relationship between Crack Initiation Stress and Loading Rate, Prefabricated Fracture Angle, and Strain Rate. The relationship between the crack initiation stress of the specimen and the loading rate is shown in Figure 13(a). The crack initiation stress of the specimens with prefabricated fracture at $0^{\circ}$ generally increased with the loading rate and slightly decreased at $11.4 \mathrm{~m} / \mathrm{s}$ and $12.2 \mathrm{~m} / \mathrm{s}$; the crack initiation stress of the specimens with prefabricated fracture at $45^{\circ}$ tended to decrease and then increase with the loading rate, the minimum crack initiation stress appeared at $11.4 \mathrm{~m} / \mathrm{s}$; under the other loading rates, the crack initiation stress tended to rise with the loading rate; the crack initiation stress of the specimens with prefabricated fracture at $90^{\circ}$ tended to increase and then decrease with the loading rate, and the values of crack initiation stress at $11.4 \mathrm{~m} / \mathrm{s}, 12.2 \mathrm{~m} / \mathrm{s}$, and $12.8 \mathrm{~m} / \mathrm{s}$ were basically the same with a slight rise. It can be inferred that the crack initiation stress of the specimens will increase with the loading rate.

The relationship between the crack initiation stress of the specimens and the prefabricated fracture angle is shown in Figure 13(b). At $9.7 \mathrm{~m} / \mathrm{s}$, the crack initiation stress continuously increased with the prefabricated fracture angle; under other loading rates, the crack initiation stress of the specimens tended to decrease then increase with the loading rate, 


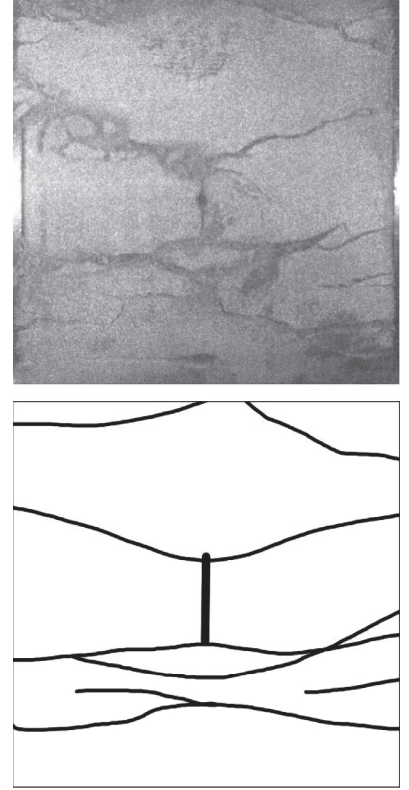

(a)
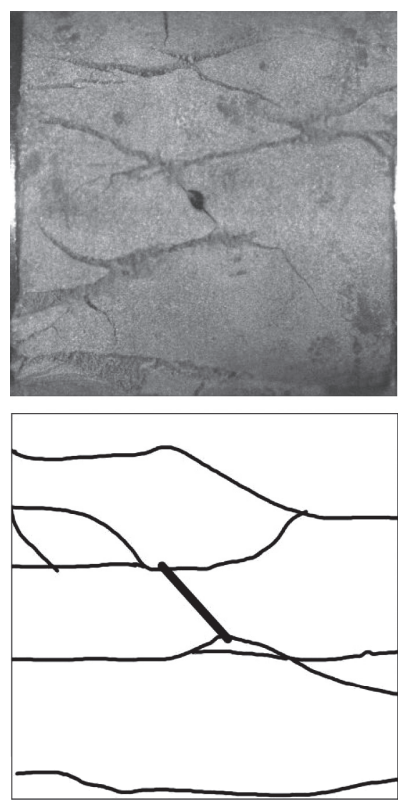

(b)

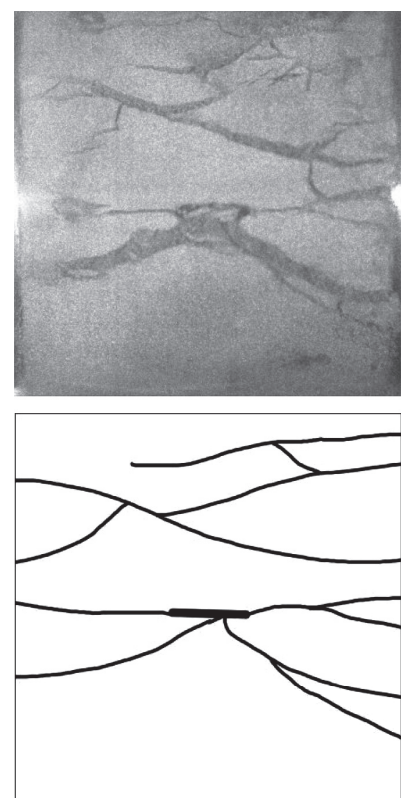

(c)

Figure 10: Final failure mode of specimens. (a) $0^{\circ}$. (b) $45^{\circ}$. (c) $90^{\circ}$.

the crack initiation stress of the specimens with prefabricated fracture at $90^{\circ}$ was greater than that of any other prefabricated fracture angle.

The relationship between the crack initiation stress of the specimens and the strain rate is shown in Figure 13(c). The crack initiation stress of the specimens with prefabricated fracture at $0^{\circ}$ increased and then decreased with the strain rate and fell at a very high velocity from $124.67 \mathrm{~s}^{-1}$ to $134.09 \mathrm{~s}^{-1}$; the crack initiation stress of the specimens with prefabricated fracture at $45^{\circ}$ tended to increase and then slightly decrease with the strain rate, at $114.31 \mathrm{~s}^{-1}, 148.64 \mathrm{~s}^{-1}$, and $175.87 \mathrm{~s}^{-1}$, and the crack initiation stress did not change, but slightly fluctuated and generally tended to rise; the crack initiation stress of the specimens with prefabricated fracture at $90^{\circ}$ increased with the strain rate, from $112.38 \mathrm{~s}^{-1}$ to $121.53 \mathrm{~s}^{-1}$, and the crack initiation stress slightly fell. It can be inferred that the crack initiation stress generally increased with the strain rate. Due to the nonuniformity of the specimens and the damage caused during the preparation process, the crack initiation stress at certain points was lower or higher than the theoretical result.

3.8. Analysis of Energy Loss Characteristics. According to prior experiments [24], the rock deformation failure in essence is energy loss. Rock impact failure is the process of energy absorption and release, and there was an iterative relationship between the rock failure subject to impact damage and the energy loss. Based on the calculation of SHPB experimental energy [24], the incident energy, the reflection energy, and the transmitted energy of the specimens during the impact loading can be calculated according to

$$
\begin{aligned}
E I & =\frac{A}{\rho \mathrm{eCe}} \int_{0}^{\tau} \sigma_{I}^{2}(t) \mathrm{dt}, \\
E R & =\frac{A}{\rho e C e} \int_{0}^{\tau} \sigma_{R}^{2}(t) \mathrm{dt}, \\
\mathrm{E}_{T} & =\frac{A}{\rho e C e} \int_{0}^{\tau} \sigma_{T}^{2}(t) \mathrm{dt},
\end{aligned}
$$

where $\sigma_{I} I(t), \sigma_{R} I(t)$, and $\sigma_{T} I(t)$ are the incident stress, the reflected stress, and the transmitted stress of the specimen at the timing point of $t, A$ is the cross-sectional area of the bar, $\rho_{e}$ is the density of the bar, and $C_{e}$ is the propagation velocity of the longitudinal wave in the bar. $\rho_{e} C_{e}$ is the wave impedance of the elastic bar.

The absorbed energy of the specimen during the impact loading was calculated according to

$$
\mathrm{E}_{S}=\mathrm{E}_{I}-\mathrm{E}_{R}-\mathrm{E}_{T}
$$

3.8.1. Relationship between Incident Energy and Loading Rate, Prefabricated Fracture Angle, and Strain Rate. The relationship between the incident energy of the specimen and the loading rate is shown in Figure 14(a). As is seen from Figure 14(a), the incident energy of the specimens with prefabricated fracture at $45^{\circ}$ and $90^{\circ}$ was almost the same at $11.4 \mathrm{~m} / \mathrm{s}$ and $12.2 \mathrm{~m} / \mathrm{s}$, the incident energy of the three groups of specimens was linearly related to the loading rate and increased with the loading rate, and the rising velocity of the incident energy was substantially the same. 


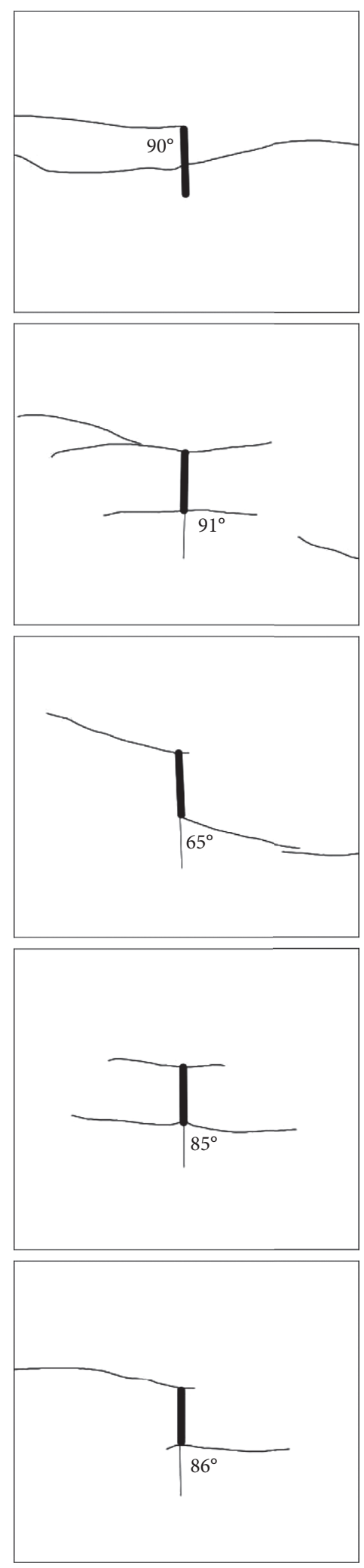

(a)
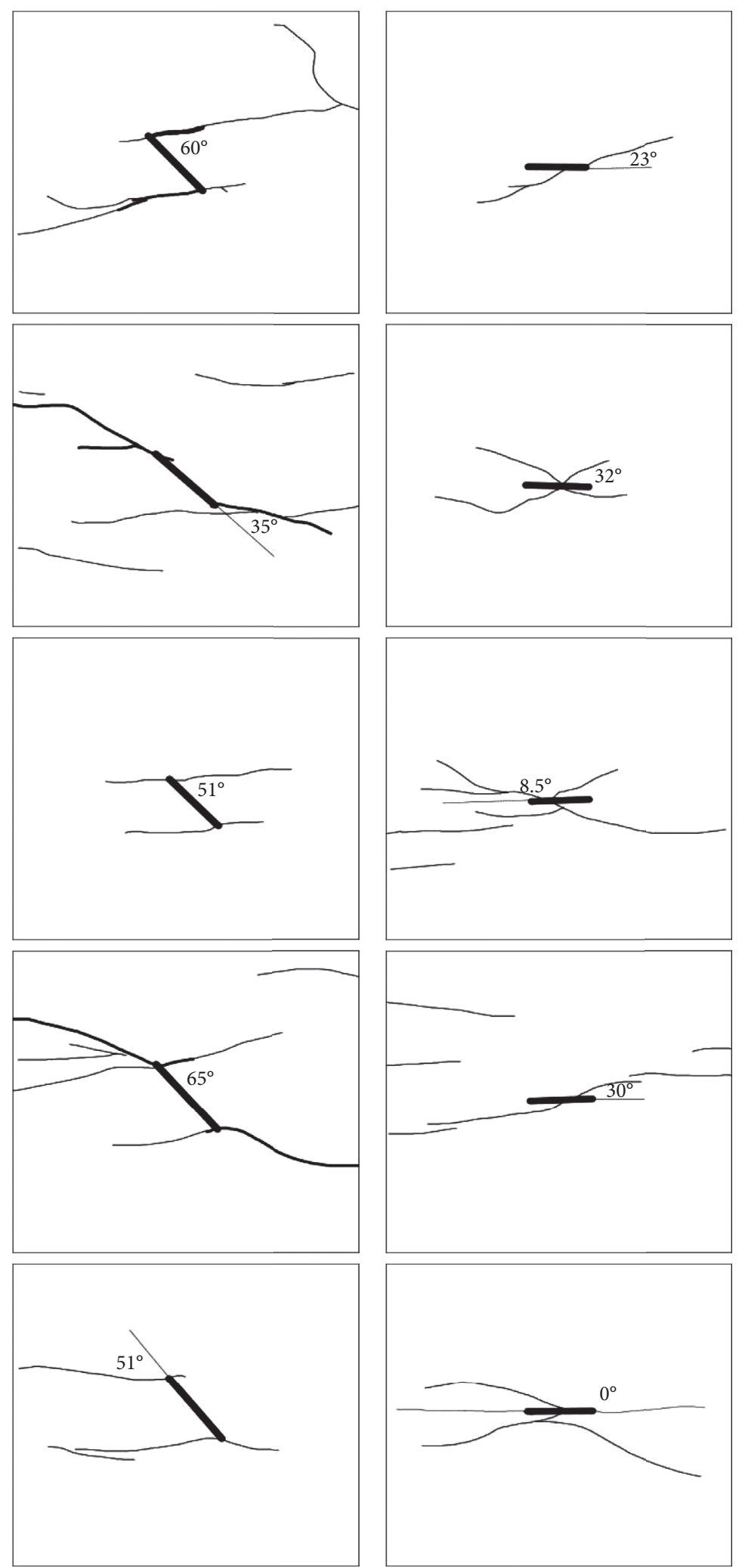

(b)
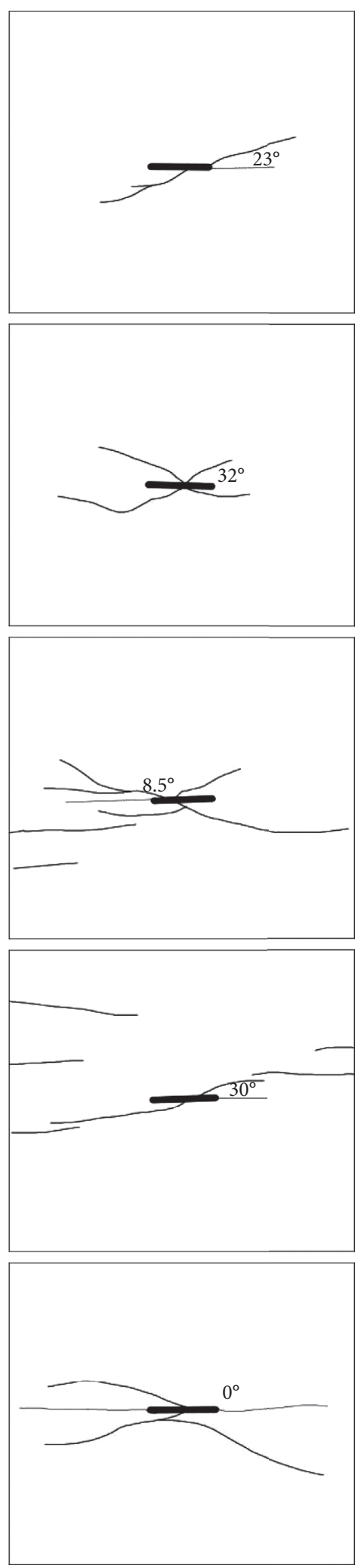

(c)

FIgURE 11: Crack initiation angle diagram. (a) $0^{\circ}$. (b) $45^{\circ}$. (c) $90^{\circ}$. 
TABLE 8: Crack initiation angle $\theta\left({ }^{\circ}\right)$.

\begin{tabular}{lccc}
\hline Loading rate $(\mathrm{m} / \mathrm{s})$ & $\mathrm{a}$ & $\mathrm{b}$ & $\mathrm{c}$ \\
\hline 9.7 & 60 & 23 & 90 \\
10.6 & 35 & 32 & 85 \\
11.4 & 51 & 8.5 & 65 \\
12.2 & 65 & 30 & 91 \\
12.8 & 51 & 91 & 86 \\
\hline
\end{tabular}

TABle 9: Crack initiation stress in MPa.

\begin{tabular}{lccc}
\hline Loading Rate $(\mathrm{m} / \mathrm{s})$ & $\mathrm{a}$ & $\mathrm{b}$ & $\mathrm{c}$ \\
\hline 9.7 & 26.97 & 29.52 & 22.64 \\
10.6 & 28.74 & 41.22 & 28.86 \\
11.4 & 23.61 & 37.46 & 27.84 \\
12.2 & 28.38 & 36.68 & 32.42 \\
12.8 & 30.07 & 38.12 & 31.43 \\
\hline
\end{tabular}

The relationship between the incident energy of the specimen and the prefabricated fracture angle is shown in Figure 14(b). As is seen from Figure 14(b), under all loading rates, the incident energy of the specimen increased and then decreased with the prefabricated fracture angle, and the incident energy of the specimen with prefabricated fracture at $90^{\circ}$ was slightly higher than that at $0^{\circ}$. The graphs of the specimens were in $\mathrm{V}$ shape, indicating that there was a critical value in $0^{\circ}-90^{\circ}$ so that the specimen can realize the maximum incident energy under the same loading rate.

The relationship between the incident energy and the strain rate is shown in Figure 14(c). As is seen from Figure 14(c), the incident energy of the specimens with prefabricated fracture at $0^{\circ}$ and $45^{\circ}$ decreased and then increased to the maximum value and then decreased again with the strain rate, and the incident energy of the specimens with prefabricated fracture at $0^{\circ}$ changed at a more drastic rate; the incident energy of the specimens with prefabricated fracture at $90^{\circ}$ tended to increase and then decrease with the strain rate, and the maximum incident energy appeared at $123.24 \mathrm{~s}^{-1}$. It can be inferred that when the prefabricated fracture angle is greater than $45^{\circ}$, the incident energy will reach a critical value as the strain rates increases; beyond this critical value, the incident energy will fall sharply as the strain rates increase; when the prefabricated angle is smaller, this change will decrease.

3.8.2. Relationship between Absorbed Energy and Loading Rate, Prefabricated Fracture Angle, and Strain Rate. The relationship between the absorbed energy and the loading rate is shown in Figure 15(a). As is seen from Figure 15(a), the absorbed energy of the specimens with prefabricated fracture at $0^{\circ}$ increased with the loading rate; when the loading rate was higher than $11 \mathrm{~m} / \mathrm{s}$, the absorbed energy increased at a slower rate; the absorbed energy of the specimens with prefabricated fracture at $45^{\circ}$ decreased and then increased with the loading rate, and the minimum absorbed energy appeared at $10.6 \mathrm{~m} / \mathrm{s}$; the absorbed energy of the specimens with prefabricated fracture at $90^{\circ}$ was the maximum at $10.6 \mathrm{~m} / \mathrm{s}$, and the minimum absorbed energy appeared at $12.2 \mathrm{~m} / \mathrm{s}$. For the absorbed energy of the specimens with prefabricated fracture at $90^{\circ}$, under the two loading rates, due to the nonuniformity of the specimens and more deviations of the absorbed energy from other data, under the other loading rates, the absorbed energy of the specimens with prefabricated fracture at $90^{\circ}$ increased with the loading rate. It can be inferred that the absorbed energy of the specimens increased with the loading rate.

The relationship between the absorbed energy of the specimens and the prefabricated fracture angle is shown in Figure 15 (b). At $9.7 \mathrm{~m} / \mathrm{s}$ and $10.6 \mathrm{~m} / \mathrm{s}$, the absorbed energy of the specimens increased and then decreased with the prefabricated fracture angle; at $11.4 \mathrm{~m} / \mathrm{s}$, the absorbed energy of the specimens hardly changed with the increase of the prefabricated fracture angle. At $12.2 \mathrm{~m} / \mathrm{s}$ and $12.8 \mathrm{~m} / \mathrm{s}$, the absorbed energy of the specimens decreased and then increased with the prefabricated fracture angle. It can be inferred that under the same loading rate, the absorbed energy of the specimens with prefabricated fracture at $0^{\circ}$ and $90^{\circ}$ was closer; under a lower loading rate $(v \leq 11.5 \mathrm{~m} / \mathrm{s})$, the absorbed energy of the specimens increased and then decreased with the prefabricated fracture; under a higher loading rate $(v>11.5 \mathrm{~m} / \mathrm{s})$, the absorbed energy of the specimens decreased and then increased with the prefabricated fracture.

The relationship between the absorbed energy of the specimens and the strain rate is shown in Figure 15(c). As is seen from Figure 15(c), the absorbed energy of the specimens with prefabricated fracture at $0^{\circ}$ decreased and then increased with the strain rate. At $134.09 \mathrm{~s}^{-1}$, the absorbed energy was too small to be considered here; the absorbed energy of the specimens with prefabricated fracture at $45^{\circ}$ decreased and then increased with the strain rate, but there was a drop in one section; the absorbed energy of the specimens with prefabricated fracture at $90^{\circ}$ tended to increase and decrease and then rebound with the strain rate. The law of variation was largely different among the three groups, but as observed from Figure 15(c), the absorbed energy of the specimens generally rose with the strain rate.

3.8.3. Relationship between Energy Absorption Rate and Loading Rate, Prefabricated Fracture Angle, and Strain Rate. Energy absorption rate is the ratio of the absorbed energy to the incident energy. The magnitude of the energy absorption rate indicates the energy consumed to break the rock mass when the specimens are subject to impact loading. In the engineering work, only a small part of the energy was usually used to damage the rock mass, and the large part of the rest energy would lead to secondary disasters. An experiment trial was conducted to identify the energy absorption rate during the rock failure process to reduce the secondary problems as a result of unused energy.

The relationship between the energy absorption rate and the loading rate is shown in Figure 16(a). As is seen from Figure 16(a), the energy absorption rate of the specimens 


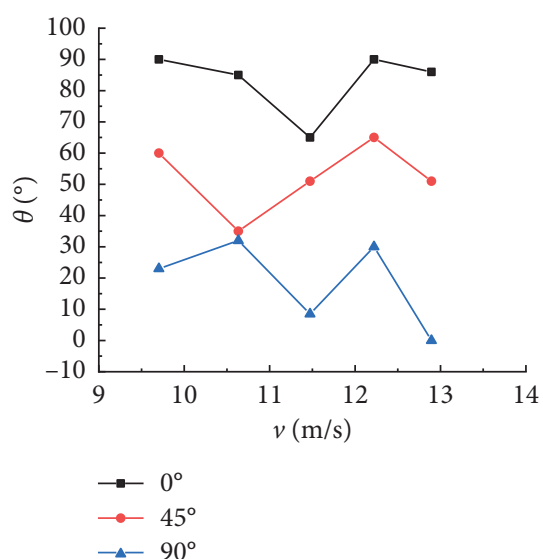

(a)

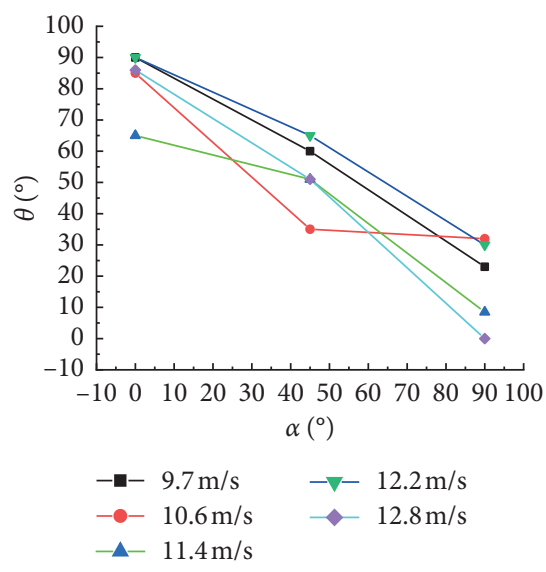

(b)

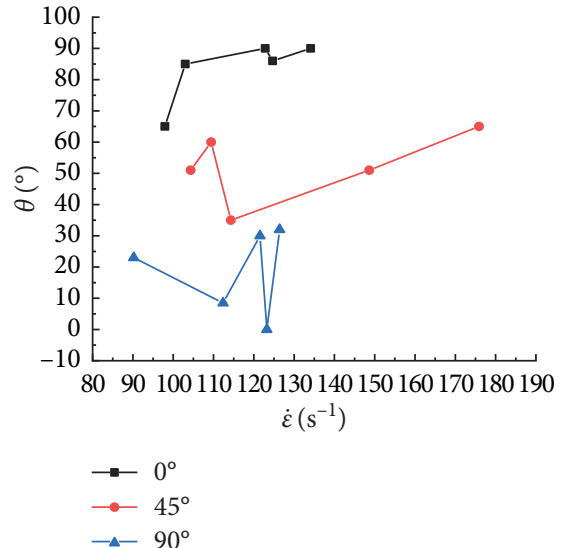

(c)

Figure 12: Relationship between crack initiation angle and loading rate, prefabricated fracture angle, and strain rate.

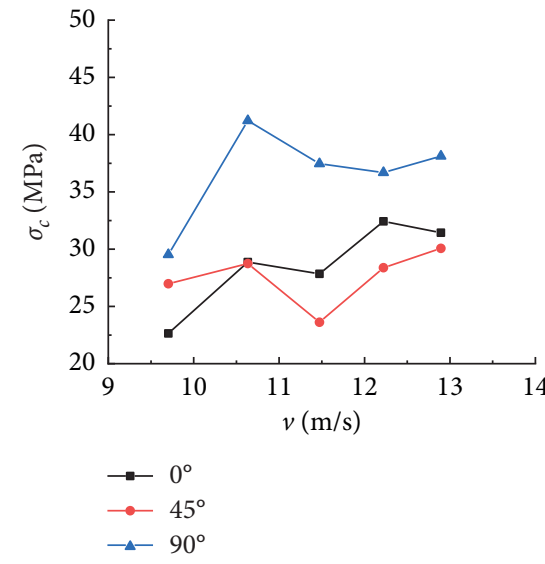

(a)

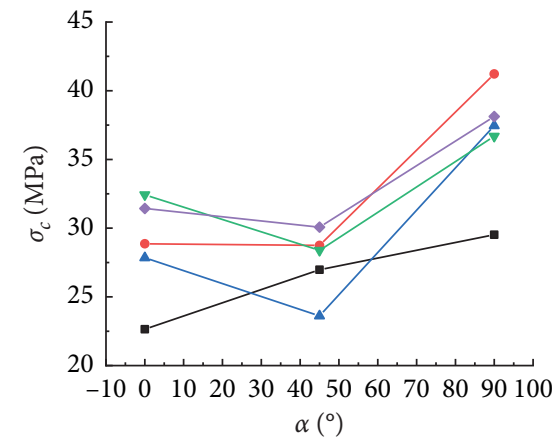

$$
\begin{array}{lll}
-\square-9.7 \mathrm{~m} / \mathrm{s} & -\nabla-12.2 \mathrm{~m} / \mathrm{s} & \rightarrow-0^{\circ} \\
-\bullet-10.6 \mathrm{~m} / \mathrm{s} & --12.8 \mathrm{~m} / \mathrm{s} & \rightarrow-45^{\circ} \\
-\Delta-11.4 \mathrm{~m} / \mathrm{s} & &
\end{array}
$$

(b)

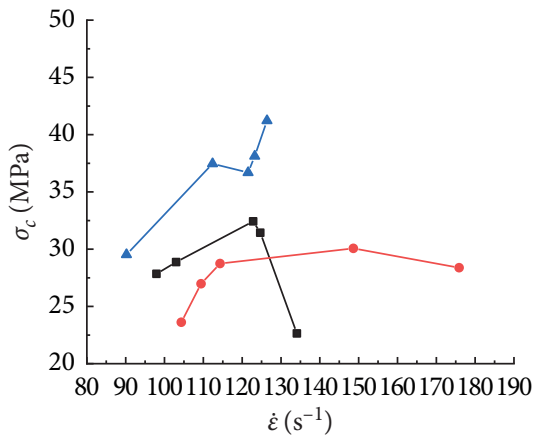

FIGURE 13: Relationship curve between crack initiation stress and loading rate, prefabricated fracture angle, and strain rate.

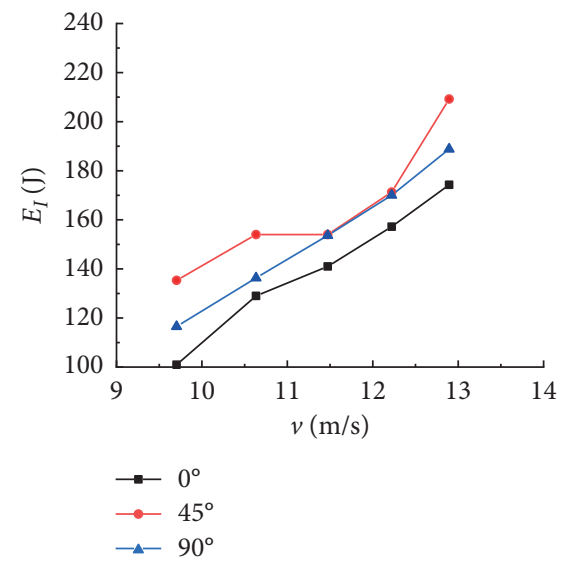

(a)

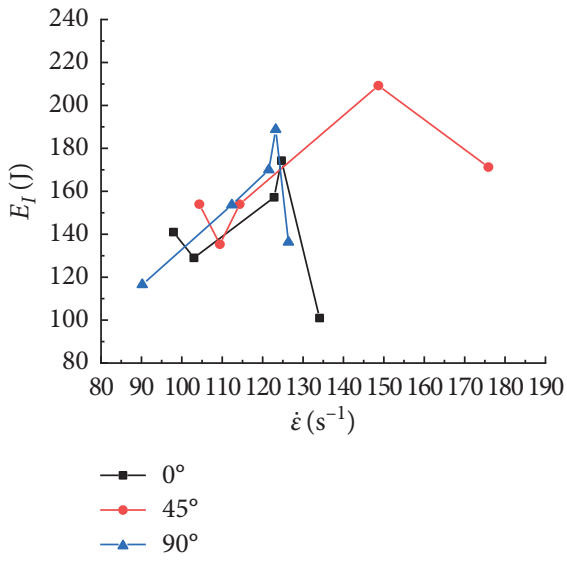

(b)

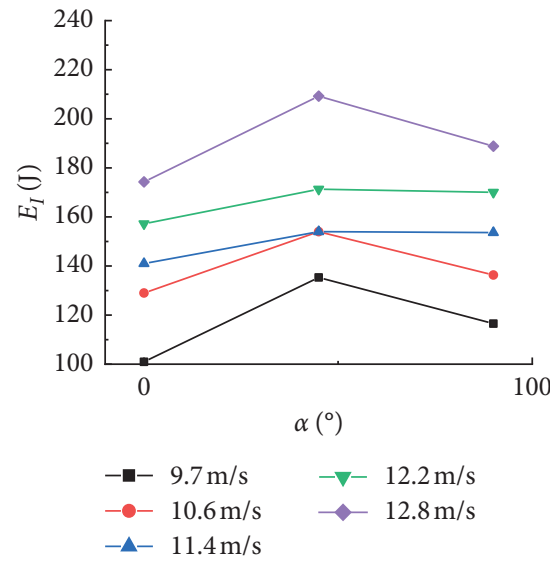

(c)

FIGURE 14: Relationship curves between incident energy and loading rate, prefabricated fracture angle, and strain rate. 


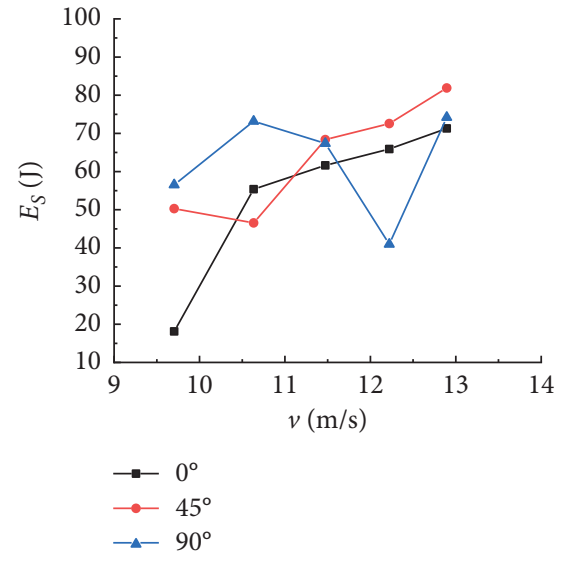

(a)

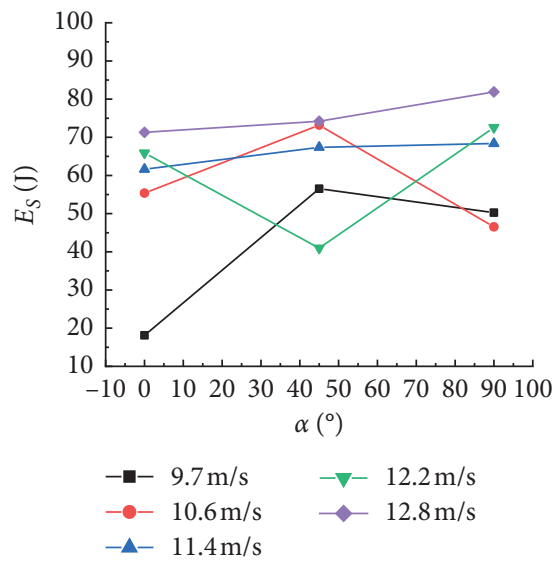

(b)

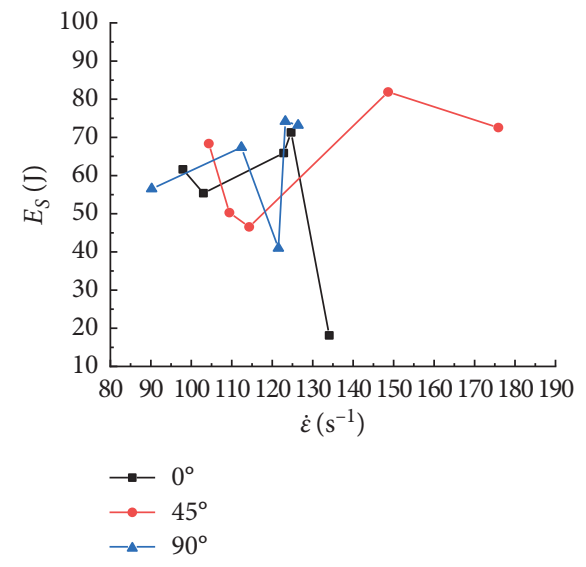

(c)

FIGURE 15: Relationship curves between absorbed energy and loading rate, prefabricated fracture angle, and strain rate.

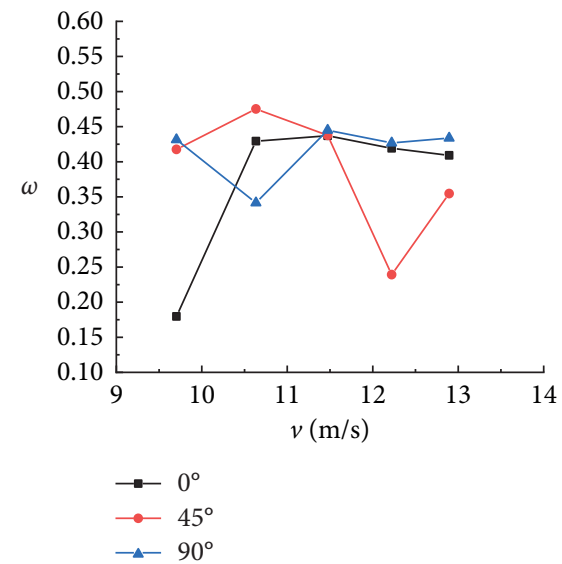

(a)

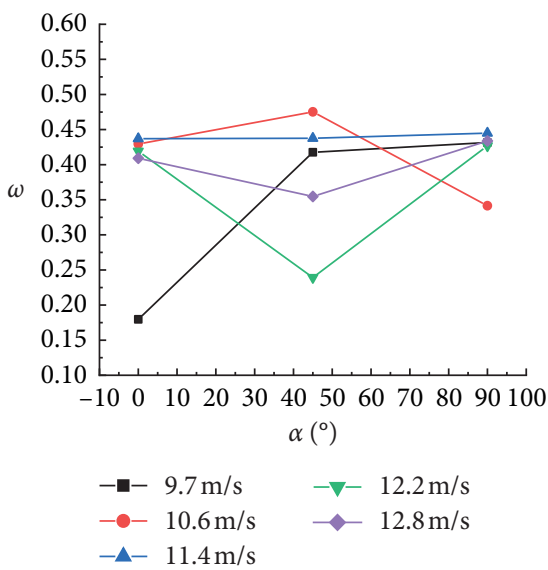

(b)

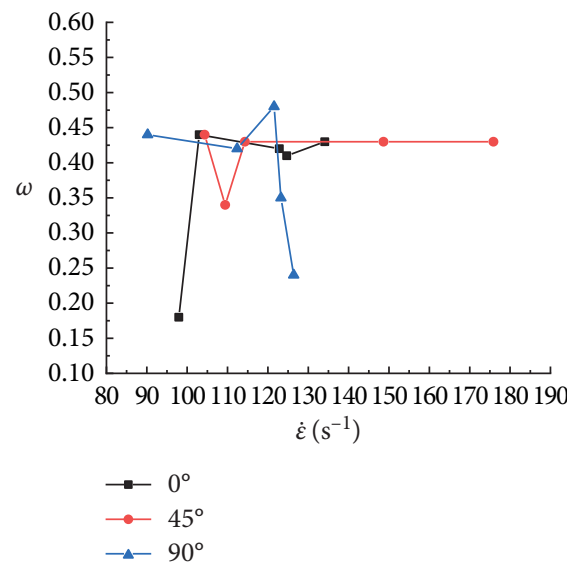

(c)

FIGURE 16: Relationship between energy absorption rate and loading rate, prefabricated fracture angle, and strain rate.

with prefabricated fracture at $0^{\circ}$ increased and then slightly decreased with the loading rate. At $10.6 \mathrm{~m} / \mathrm{s}$ and $11.4 \mathrm{~m} / \mathrm{s}$, the energy absorption rate was almost the same, namely, the maximum energy absorption rate for the specimens with prefabricated fracture at $0^{\circ}$; the energy absorption rate of the specimens with prefabricated fracture at $45^{\circ}$ increased and decreased and then rebounded, the maximum energy absorption rate appeared at $10.6 \mathrm{~m} / \mathrm{s}$, and the minimum energy absorption rate appeared at $12.2 \mathrm{~m} / \mathrm{s}$; the specimens with prefabricated fracture at $90^{\circ}$ fell and then rose and finally remained the same. It can be inferred that the energy absorption rate of the specimens generally tended to get close to $43 \%$ with the loading rate, the energy absorption rate of the specimens with prefabricated fracture at $45^{\circ}$ was slightly lower, and there was a fracture angle between $0^{\circ}$ and $90^{\circ}$, making the energy absorption rate up to the minimum value.

The relationship between the energy absorption rate and the prefabricated fracture angle is shown in Figure 16(b). As is seen from Figure $16(\mathrm{~b})$, at $9.7 \mathrm{~m} / \mathrm{s}$ and $10.6 \mathrm{~m} / \mathrm{s}$, the energy absorption rate rose and then fell; at $11.4 \mathrm{~m} / \mathrm{s}$, the energy absorption rate hardly changed with the prefabricated fracture angle; at $12.2 \mathrm{~m} / \mathrm{s}$ and $12.8 \mathrm{~m}$, the energy absorption rate decreased and then increased with the prefabricated fracture angle. At $0^{\circ}$ and $90^{\circ}$, the energy absorption rate of the specimens hardly changed but fluctuated around $43 \%$; the specimens with prefabricated fracture at $45^{\circ}$ changed at a higher rate with the loading rate. For details, refer to the previous paragraph.

The relationship between the energy absorption rate and the strain rate is shown in Figure 16(c). As is seen from Figure 16(c), at $97.94 \mathrm{~s}^{-1}$, the energy absorption rate (18\%) of the specimens with prefabricated fracture at $0^{\circ}$ was much lower than that at any other loading rate; the energy absorption rate of the specimens with prefabricated fracture at $0^{\circ}$ and $45^{\circ}$ basically did not change with the strain rate, and all fluctuated around the energy absorption rate of $43 \%$; below $120 \mathrm{~s}^{-1}$, the energy absorption rate of the specimens with prefabricated fracture at $90^{\circ}$ slightly fell; beyond $121 \mathrm{~s}^{-1}$, it rapidly fell with the strain rate. 


\section{Conclusion}

(1) Under dynamic loading, the dynamic compressive strength, peak strain, and dynamic elastic modulus of the specimens increased with the loading rate; the dynamic compressive strength and dynamic elastic modulus of the specimens decreased and then increased with the prefabricated crack angle, and the peak strain tended to increase and then decrease; under a high strain rate, all three parameters increased with the strain rate.

(2) Under dynamic loading, the primary crack propagation of the specimens increased with the prefabricated fracture angle, the primary crack was formed by shear and tension in a transition to shear splitting; the primary crack propagation of the specimens was also subject to the loading rate. Although the starting mode of the primary crack propagation was basically the same, the velocity increased with the loading rate. The cracks on all specimens propagated and connected in the direction of impact loading.

(3) The crack initiation angle of the specimens at different loading rates hardly changed, and it can be inferred that the loading rate had little influence on the crack initiation angle or there was only extremely small difference; the crack initiation angles of these three groups of specimens with prefabricated fracture were centrally symmetric along the center of the prefabricated fracture, and the crack initiation angle gradually decreased with the prefabricated fracture; under a high strain rate, the crack initiation angle of the specimens tended to rise with the strain rate.

(4) With the change of the loading rate, the crack initiation stress fluctuated. As the loading rate increased, it rose and then fell continuously; the crack initiation stress increased and then decreased with the prefabricated fracture angle; and under a high stress rate, the crack initiation stress generally increased with the stress rate.

(5) The incident energy and the absorbed energy increased with the loading rate, the incident energy tended to decrease and then increase with the prefabricated fracture angle, and there was a certain angle around $45^{\circ}$ that made the incident energy maximum; under the same loading rate, the absorbed energy of the specimens with prefabricated fracture at $0^{\circ}$ and $90^{\circ}$ was closer; under a lower loading rate $(v \leq 11.5 \mathrm{~m} / \mathrm{s})$, the absorbed energy of the specimens increased and then decreased with the prefabricated fracture; under a higher loading rate $(v>11.5 \mathrm{~m} / \mathrm{s})$, the absorbed energy of the specimens decreased and then increased with the prefabricated fracture; the energy absorption rate of the specimens changed a little with the change of loading rate and prefabricated fracture angle but fluctuated around $43 \%$; under a higher strain rate, as the strain rate increased, the incident energy would occur at a critical maximum value, and the absorbed energy tended to rise, but the energy absorption rate hardly changed.

\section{Data Availability}

All the data used to support the findings of this study are included within the article.

\section{Conflicts of Interest}

The authors declare that there are no conflicts of interest regarding the publication of this paper.

\section{Acknowledgments}

The authors would like to thank the National Natural Science Foundation of China (no. 51704295) and Basic Scientific Research Expenses of Central Universities for their support.

\section{References}

[1] F. Jiang and K. S. Vecchio, "Hopkinson bar loaded fracture experimental technique a critical review of dynamics fracture toughness tests," Applied Mechanics Reviews, vol. 62, no. 6, pp. 60-80, 2009.

[2] R. Yang, Y. Wang, and C. Ding, "Laboratory study of wave propagation due to explosion in a jointed medium," International Journal of Rock Mechanics and Mining Sciences, vol. 81, pp. 78-90, 2016.

[3] M. Yang and Y. He, "Analysis of properties of broken rock," Journal of China University of Mining \& Technology, vol. 31, no. 1, pp. 9-13, 2001.

[4] P. Zhang, L. Ning, and R. He, "Research on localized progressive damage model for fracture rock-like materials," Chinese Journal of Rock Mechanics and Engineering, vol. 25, no. 10, pp. 2043-2050, 2006.

[5] S. Yang, X. Liu, and Y. Li, "Experimental analysis of mechanical behavior of sandstone containing hole and fissure under uniaxial compression," Chinese Journal of Rock Mechanics and Engineering, vol. 31, no. S2, pp. 3539-3546, 2012.

[6] H. Su, H. Jing, H. Zhao, and Y. Wang, "Experimental study on the influence of longitudinal fissure on mechanics characteristic of sandstone," Journal of Mining \& Safety Engineering, vol. 31, no. 4, pp. 644-649, 2014.

[7] D. Li, J. Qiu, and X. Li, "Experimental study of dynamic tensile and compressive properties of bedding sandstone under impact loading," Chinese Journal of Rock Mechanics and Engineering, vol. 34, no. 10, pp. 2091-2097, 2015.

[8] D. Li, Z. Han, X. Sun, and X. Li, "Characteristics of dynamic failure of marble with artificial flaws under split Hopkinson pressure bar tests," Chinese Journal of Rock Mechanics and Engineering, vol. 36, no. 12, pp. 2872-2883, 2017.

[9] C. Xia, H. Li, and S. Liu, "Study of deformation properties of joined specimens under unloading conditions," Chinese Journal of Rock Mechanics and Engineering, vol. 36, no. 12, pp. 2872-2883, 2017.

[10] X. Xu, Research on Characteristics of Crack Evolution of Rocklike Material Containing Joid Acoustic emission, China University of Mining \& Technology, Xuzhou, China, 2016.

[11] H. Xie, Ju Yang, and L. Li, "Criteria of strength and structural failure of rocks based on energy dissipation and energy release 
principles," Chinese Journal of Rock Mechanics and Engineering, vol. 24, no. 17, pp. 3003-3010, 2005.

[12] Y. Gao, N. Gong, and Y. Luo, "Experimental study on dynamic fracture toughness of rock," Journal of Anhui University of Science and Technology (Natural Science), vol. 32, no. 1, pp. 13-16, 2012.

[13] Y. Deng, M. Chen, J. Yan, and D. Zhou, "Investigation of the dynamic characteristics and energy consumption for breaking rocks using the impact load," Petroleum Drilling Techniques, vol. 44, no. 3, pp. 27-32, 2016.

[14] Y. Wang and R. Yang, "Study of the dynamic fracture characteristics of coal with a bedding structure based on the NSCB impact test," Engineering Fracture Mechanics, vol. 184, pp. 319-338, 2017.

[15] Y. Wang, "Analysis of dynamic characteristics of through-wall cracks between 2 boreholes in the directed fracture controlled blasting," Fatigue \& Fracture of Engineering Materials \& Structures, vol. 41, no. 2, pp. 273-286, 2018.

[16] Y. Wang, "Rock dynamic fracture characteristics based on NSCB impact method," Shock and Vibration, vol. 2018, Article ID 3105384, 13 pages, 2018.

[17] T. Yokoyama and K. Kishida, "A novel impact three-point bend test method for determining dynamic fracture-initiation toughness," Experimental Mechanics, vol. 29, no. 2, pp. 188194, 1989.

[18] A. G. Dutton and R. A. W. Mines, "Analysis of the Hopkinson pressure bar loaded instrumented Charpy test using an inertial modelling technique," International Journal of Fracture, vol. 51, pp. 187-206, 1991.

[19] M. Prudencio and M. Van Sint Jan, "Strength and failure modes of rock mass models with non-persistent joints," International Journal of Rock Mechanics and Mining Sciences, vol. 44, no. 6, pp. 890-902, 2007.

[20] L. N. Germanocich and A. V. Dyskin, "Fracture mechanisms and instability of openings in compression," International Journal of Rock Mechanics and Mining Sciences, vol. 37, no. 12, pp. 263-284, 2000.

[21] E. Gaziev and V. Levtchouk, "Strength characterization for rock under multiaxial stress states," in Proceedings of the 9th International Congress on Rock Mechanics, Paris, France, August 1999.

[22] E. Gaziev, "Rupture energy evaluation for brittle materials," International Journal of Solids and Structures, vol. 38, no. 4243, pp. 7681-7690, 2001.

[23] D. Huang, R. Huang, and Y. Zhang, "Experimental investigations on static loading rate effects on mechanical properties and energy mechanism of coarse crystal grain marble under uniaxial compression," Chinese Journal of Rock Mechanics and Engineering, vol. 31, no. 2, pp. 245-255, 2012.

[24] Z. Han, "Material behaviour characterisation using SHPB techniques, tests and simulations," Computers and Structures, vol. 81, no. 12, pp. 1301-1310, 2003. 